\title{
Geometric issues and ultimate load capacity of masonry arch bridges from the northwest Iberian Peninsula
}

\author{
Daniel V. Oliveira ${ }^{1}$, Paulo B. Lourenço ${ }^{2}$ and Cláudia Lemos ${ }^{3}$ \\ ISISE, University of Minho, Department of Civil Engineering, Guimarães, Portugal
}

\begin{abstract}
This paper reports the results from a geometrical survey carried out on 59 segmental masonry arch bridges from Portugal and Spain, with a focus on the adjacent geographical areas of northern Portugal and northwestern Spain. Historical empirical rules are briefly presented and further compared against the bridges' geometrical data. Departing from a detailed discussion of the geometrical results, eight reference bridges were defined as representative of the sample. Subsequently, the paper deals with a parametric assessment of the loadcarrying capacity of the reference bridges and a discussion of results. It was found that arch thickness and physical properties of the fill are of paramount importance in terms of ultimate load-carrying capacity. Furthermore, the results indicate that the bridges from the sample are structurally safe with respect to applicable legislation.
\end{abstract}

Keywords: masonry arch bridges, ultimate load, limit analysis, collapse mechanism, empirical rules

${ }^{1} \mathrm{PhD}$, Assistant Professor, ISISE, University of Minho, Department of Civil Engineering, Azurém, P-4800-058 Guimarães, Portugal. Phone: +351 253510 247, fax: +351 253510 217, email: danvco@ civil.uminho.pt

${ }^{2} \mathrm{PhD}$, Professor, ISISE, University of Minho, Department of Civil Engineering, Azurém, P-4800-058 Guimarães, Portugal. Phone: +351 253510 209, fax: +351 253510 217, email: pbl@ civil.uminho.pt

${ }^{3}$ MSc, University of Minho, Department of Civil Engineering, Azurém, P-4800-058 Guimarães, Portugal 


\section{Introduction}

The use of arches and vaults to span horizontal spaces is several thousand years old. The first arches were found in underground tombs in Mesopotamia, built around 3000 BC [1]. Besides the Sumerians, the Egyptians and Greeks also knew vault and arch structures [2]. Following a long process of evolution, Etruscans are considered the first to have built masonry arches using wedge stones. Later on, Romans not only improved arch construction techniques but also added pozzolanic mortar [2]. With the decline of the Roman Empire, around the 5th century, the road system, including the bridges, suffered a significant degradation. Six centuries later, the occurrence of important economic and social changes in Europe caused an increase in economic activity, requiring the construction of new roads and bridges. The construction of masonry arch bridges returned to Europe with splendour.

The ensemble of European masonry arch bridges is a result of centuries of hard and delicate work, thus representing an invaluable architectural and cultural heritage. Nowadays, it is still possible to find Roman bridges, characterized by their flat pavements and identical semicircular arches, as well as the more flexible mediaeval bridges, with larger central spans, semicircular or pointed arches, cutwaters and humpback pavements. However, the successive maintenance and repair works to which bridges were submitted through the centuries has generally led to difficulties in the dating process, resulting in sometimes erroneous classification [3]. With time, the significant change in load from those for which bridges were initially built, the unavoidable decay of materials and a persistent lack of maintenance have led to varying degrees of damage, with many bridges now not compatible with their current use and some even structurally unsafe.

Following earlier developments (e.g. [4-6]), the last two decades have witnessed very important advances concerning the mechanics of masonry arch bridges. These advances include the development of methods for the computation of load-carrying capacities involving different degrees of complexity (e.g. [7-10]) and of assessment techniques based on non-destructive testing methods (e.g. [11]). The few works carried out on masonry arch bridges in Portugal [12-19] have centred on geometrical and architectural descriptions, surveys of damage and strengthening possibilities, while structural analysis and assessment are almost absent. As a consequence, the structural safety of Portuguese masonry arch bridges is hardly known. This paper encompasses the study of a sample of 59 roadway masonry arch bridges, including geometrical and structural analysis of the sample and comparison with historical empirical rules. The main objectives are the characterization of the geometry of bridges constructed in adjacent geographical areas and the achievement of rapid screening of 
structural safety of the sample based on geometrical information and relatively simple numerical tools. The research work carried out is based on the following steps:

- geometrical survey of Portuguese and Spanish masonry arch bridges supported in the existing literature, with a focus on the adjacent geographical areas of northern Portugal and north-western Spain;

- analysis of the main historical empirical rules used to build bridges and their comparison with survey data;

- definition of reference bridges geometrically representative of the sample;

- numerical assessment of the ultimate load-carrying capacity of the reference bridges, including parametric analysis of the most influential geometrical, physical and mechanical parameters.

The first part of the paper deals with the presentation and discussion of results from the geometrical survey, their comparison with historical empirical rules and definition of the referenced single and multi-span bridges. The second part of the paper focuses on the parametric numerical analysis and discussion of the most important parameters that control the ultimate load capacity of single and multi-span masonry arch bridges.

\section{$2 \quad$ Empirical rules}

Prior to the application of statics to masonry arches, initiated by La Hire in the first half of the 18th century, the design process of arch bridges involved the use of empirical rules, which were based on simple geometrical relations and aimed at providing both the dimensions of several bridge components (span, rise and thickness of arch, width and height of piers, etc.) and the safety of the structure based on past experience. Although empirical rules are hardly justified from a mechanical point of view, most of them are revealed to be efficient. Following the works of La Hire, Couplet, Bélidor and many other authors, methods of analysing masonry arch bridges were essentially based on graphic statics. However, establishing the structural form of bridges via an empirical approach continued to be popular, due to builders lacking knowledge of the mathematics and mechanics required to understand and perform static analysis.

\subsection{Shape of the arch}

The shape of an arch is described as a function of the span $s$ and rise $r$ or, more normally, of the rise to span ratio $r / s$. Roman arch bridges were typically semicircular $(r / s=1 / 2)$, though segmental arches $(r / s<1 / 2)$ were also found. During the mediaeval period, the pointed arch form was introduced. Also, the semicircular shape of Roman arches was reintroduced at the beginning of the Renaissance, but its restricted functionality in urban areas gave rise to new arch forms, which were shallower than the Roman arch. At this time the three-centred 
arch (basket arch), the ellipse and the inverted catenary were introduced, serving both aesthetic and practical requirements. The S. Trinità Bridge (basket arch) built in 1569 in Italy is the first example of the use of these new forms [20].

\subsection{Thickness of the arch}

The thickness of an arch bridge can be constant or variable. Typically, arch thickness at the crown was taken from similar existing bridges or based on empirical rules of which there are several, involving varying degrees of complexity. In these, thickness at the crown $t$ is related to span $s$ (or span-related parameters) through different mathematical relationships, but for a detailed discussion and possible classification the reader is referred to Albenga [21] or Proske and van Gelder [2]. Many empirical equations were proposed, mainly during the 19th century. The most well-known expressions [2, 20-23] are listed in Table 1 for deep arches only. These equations represent an asymptotic decrease of thickness with thickness to span ratio, not factoring in Alberti's rule. There is reasonable agreement among empirical rules, except for the proposals of Alberti and Gautier. The upper limit is defined by the equation of Lesguillier (19th century) for spans up to $6 \mathrm{~m}$ and by the rule of Alberti (15th century) for larger spans, while the lower limit is controlled by the equation of Rankine (19th century).

\subsection{Width of piers}

The definition of pier width does not depend only on stability issues, being often conditioned by aesthetic aspects. For instance, the minimum geometrical value of pier width for semicircular arches is given by the sum of the thickness of adjacent arches at springing. Furthermore, it is possible that hydrodynamic effects had also been empirically considered [2] in the establishment of the width of piers. In an example of an empirical rule, Campanela [22] states that the width of piers typically varies between $1 / 5$ and $1 / 10$ of the span.

\section{Geometrical study}

\subsection{Geometrical survey}

A survey of the most important geometrical properties of ancient roadway masonry arch bridges was carried out based on available literature reviews and previous studies [12-16, 24-25]. In total, 59 bridges from Portugal and Spain were considered, with an emphasis on bridges located in the adjacent geographical areas of Minho and Trás-os-Montes provinces (northern Portugal) and the Galicia region (north-western Spain). Indeed, $70 \%$ of the surveyed bridges are located in these areas. The predominance of these two geographical areas is essentially due to the existence and availability of data. As the University of Minho is located in Minho province, visits to local 
bridges were possible and it was also expected that the geographical proximity of the two areas might have led to the use of similar construction techniques [23].

The 59 roadway bridges analyzed are constituted by segmental arches, either single or multi-span bridges, totalling 207 spans. However, some surveyed bridges not considered in this study are simultaneously composed of segmental and pointed arches, due to important repair works performed after partial failures that took place in the past. The non-geometrical parameters analyzed were the material used in the structure and the place and date of construction. In terms of the construction material used to build arches and piers, it was found that $79 \%$ of the bridges are made of granite, with other structural materials used being limestone, sandstone and schist. All bridges spanning more than $16 \mathrm{~m}$ are made of granite, which is an expected result as granite is the dominant rock in the northern part of Portugal. In terms of location, $72 \%$ of the bridges from the sample are located in Portugal. This result is obviously conditioned by the availability of and access to data. The date of construction is a very difficult parameter to assess, but based on the available information $67 \%$ of the bridges were built before the 15th century. This large percentage of historical bridges in the sample is not completely representative of the Portuguese reality, because existing available data is typically more abundant for historical bridges than for less ancient and less well known examples.

The geometrical parameters collected were the number of spans, clear span $s$, rise $r$, crown thickness of arches $t$ and the width $W$ and height $H$ of piers. Pier height is here considered as the distance from foundation to springing. Multi-span bridges are dominant within the sample, comprising $71 \%$ of bridges. Three classes were considered for the rise to span ratio (or relative depth):

$$
\begin{array}{ll}
\text { - shallow arch } & 0.00<r / s \leq 0.25 \\
\text { - semi-shallow arch } & 0.25<r / s \leq 0.40 \\
\text { - deep arch } & 0.40<r / s
\end{array}
$$

In addition, bridges were also grouped into three categories as a function of their span:

$$
\begin{array}{ll}
\text { - short span bridge } & 0.0<s \leq 7.5 \quad(\mathrm{~m}) \\
& \\
\text { - medium span bridge } & 7.5<s \leq 15.0 \quad(\mathrm{~m}) \\
\text { - large span bridge } & 15.0<s \quad(\mathrm{~m})
\end{array}
$$

The relationship between span, rise and rise to span ratio is illustrated in Fig. 1 for all arches within the sample. The sample is dominated by arches spanning up to $12 \mathrm{~m}$. Most of the few large span bridges are located in Spain and were built during the Roman period. Deep and semi-shallow arch shapes are dominant, with an average relative depth of about 0.40 . However, rise to span ratios larger than 0.50 are not usually seen in 
segmental arch bridges and, most probably, are due to errors in available geometrical data. Furthermore, different bibliographical sources sometimes provide conflicting data for the same bridge.

In order to provide a more detailed geometrical analysis, three ratios were computed for each arch: rise to span ratio $(r / s)$, thickness to span ratio $(t / s)$ and thickness to rise ratio $(t / r)$. The relationship between them is graphically illustrated in Fig. 2, Fig. 3 and Fig. 4, for the three span categories considered. Short and medium span arches make up the large majority of the arches surveyed, while less than $5 \%$ have a span larger than $15 \mathrm{~m}$ (also see Fig. 1). Moreover, most of the arches present a relative depth higher than 0.25 . This result means that the arches within the sample might be well represented by semi-shallow to deep arches with short to medium spans.

Although not distinguished in Fig. 2, Fig. 3 and Fig. 4 for the sake of readability, the various geometrical ratios of Portuguese and Spanish bridges are quite similar [19], indicating that their geographical proximity most probably promoted the use of the same empirical rules. The only difference concerns large span bridges, with all bridges with spans larger than $20 \mathrm{~m}$ located in Spain. The bridges built before the 15 th century also tend to exhibit higher thickness to span ratios than the less ancient bridges. This result is in accordance with the historical improvement of empirical design rules used through the centuries.

The empirical rule comparison, discussed in section 2.2, and the survey data regarding crown thickness are illustrated in Fig. 5. Many bridges within the sample present thickness to span ratios above the upper envelope limit, particularly short span arches which might be associated with the use of more conservative design rules than those provided in Table 1. It is also possible that most short span arches were built by less qualified masons, due to their reduced importance to the road network. The large number of bridges built before the 15 th century present in the sample also contributes to this result.

In terms of the multi-span bridges ( $71 \%$ of the sample), piers were also included in the geometrical survey. However, pier height is often a difficult parameter to characterize, due to a lack of knowledge of flow depth and type of foundation. Fig. 6 represents the relationship between the span and width to span ratio, with the span value used calculated as the average of adjacent span values. It can be seen that the width to span ratio is relatively constant for spans larger than $14 \mathrm{~m}$, with an average value of 0.26 . This value is $30 \%$ higher than the upper limit indicated by Campanela [22]. On the other hand for spans less than $14 \mathrm{~m}$, the width to span ratio tends to increase with decreasing span. It is important to mention that this span range includes bridges from all historical periods and is not dominated by the most ancient bridges. These results indicate that pier width is not linearly proportional to span and needs to be further increased for medium to short spans. A qualitative trend line 
is also illustrated in Fig. 6. Two main reasons might explain this feature: (a) the existence of more piers in the river flow may represent the need to use stockier piers for safety against floods and strong water stream flow; (b) short span bridges were probably built by less qualified masons, thus leading to the adoption of a more conservative pier width.

For the piers, two ratios were computed from the geometrical survey; width to span $\mathrm{W} / \mathrm{s}$ and height to width $H / W$. These ratios were correlated with relative depth in Fig. 7, Fig. 8 and Fig. 9 for short, medium and large span bridges, respectively. The diagrams show significant variation in values, with it being difficult to define any trends. For short span bridges and semi-shallow arches, the dominant value of $W / s$ is around 0.50 , while for deep arches it seems to be slightly higher. For medium span bridges, the dominant value of $\mathrm{W} / \mathrm{s}$ is around 0.30 for both semi-shallow and deep arches. This conclusion is in agreement with the results shown in Fig. 6 . The height to width ratio is barely higher than 4 , being generally less than 2 . The four values of height to width ratio higher than 6.5 belong to a single bridge with slender piers and are an exception. The low height to width ratios found seem to be in opposition to the empirical relation provided by Alberti in the 15th century [21], in which it was stated that $H=4 W$. Analysis according to date of construction shows that the bridges built before the 15 th century (which represent $67 \%$ of the sample) tend to exhibit stockier piers [19].

\subsection{Reference bridges}

Based on data provided in Fig. 2, Fig. 3 and Fig. 4, four single span reference bridges (i.e. idealized bridges) were defined as being geometrically representative of the whole sample, as shown in Table 2 with two bridges schematically represented in Fig. 10. Neither large span nor shallow bridges were considered due to their reduced presence in both the sample and the northwest Iberian Peninsula. Analysis of the load capacity of reference bridges A, B, C and D will provide rapid screening of the structural safety of the sample.

Arch thickness was defined according to the results exhibited in Fig. 2 and Fig. 3, by considering representative values. For the other geometrical parameters, current values found in bridges from the northwest Peninsular were assumed [26-27]. The number of voussoirs was calculated assuming a usual thickness at intrados equal to $0.35 \mathrm{~m}$. The effective bridge width was estimated according to the few existing publications [28-29], assuming a constant effective width equal to geometric bridge width (4.0 m). In addition, a fill depth above the crown of about $0.4 \mathrm{~m}$ was adopted. Parameters influencing structural response, such as effective arch thickness, the possible existence of backing material and the nature and characteristics of the filling material, were not available in the bibliographic survey (as these parameters are not typically assessed) and therefore 
conservative values have been adopted for the reference bridges. This requires that non-destructive techniques should be used together with detailed visual inspections [11, 30-31].

\section{$4 \quad$ Ultimate load-carrying capacity of single span bridges}

The ultimate load carried by a masonry arch bridge essentially depends on arch and fill properties. The arch is the structural element responsible for transferring the load to abutments and piers, while the soil adds dead weight, disperses the applied load at the surface and provides horizontal restraint to movements of the arch.

\subsection{Numerical analysis}

Several methods and computational tools are currently available to simulate the structural response of masonry arch bridges. Naturally, different constitutive models produce structural models that involve varying levels of complexity. The most common idealizations of material behaviour are elastic, plastic and nonlinear and for a detailed discussion the reader is referred to Lourenço [32]. Among the available computational methods proposed in the literature with which to evaluate the load-carrying capacity of masonry arch bridges, the rigid block computational limit analysis method is the most generally applicable $[7,10]$. Within this method, the load distribution is known while the load magnitude that the bridge can carry is unknown, but can be easily calculated. This makes limit analysis a very practical computational tool since it requires a reduced number of material parameters while providing a good insight into failure patterns and limit loads. The applicability of limit analysis to masonry structures modelled as assemblages of rigid blocks connected through joints depends on few basic hypotheses, all of which are usually acceptable in the case of stone arch bridges [33].

This study used the computer software Ring 1.5 [34-35], designed to calculate the ultimate load-carrying capacity of masonry arch bridges. This software is based on the rigid block limit analysis method, in which single or multi-span bridges are modelled as in-plane structures and arches as assemblages of rigid blocks. The collapse state (collapse load and collapse mechanism) is also computed through the use of limit analysis. For further software details, the reader is referred to [10, 34-35].

Bridge geometry, loading and material properties of the arches and fill data were entered into Ring 1.5. The geometry of the reference bridges was fully defined, based on the geometrical survey and on current values found in similar bridges. Besides the self-weight of the materials (masonry and fill), a live load composed of a standard Portuguese vehicle [36] was considered. This standard vehicle is composed of three axles spaced equally $1.5 \mathrm{~m}$ apart, with a load of $100 \mathrm{kN}$ per axle and a width of $2.0 \mathrm{~m}$. With regard to material properties and in the absence of comprehensive in-situ test results, these were considered to assume typical values found in 
similar surveyed bridges [26-27] (see Table 3). In particular, load dispersion through the fill was modelled according to the classical Boussinesq distribution with a dispersion angle of $30^{\circ}$, while an earth pressure coefficient $k_{\mathrm{p}}$, based on the Rankine theory and equal to half of the value adopted for arches, was also used [37].

The ultimate load-carrying capacity is expressed in terms of a load factor, which is the ratio between the collapse load and the live load, comprised of a standard vehicle. Obviously, a different load factor is associated with each possible location of the moving vehicle, meaning that the minimum value of all possible load factors is the only one of interest. Besides the minimum load factor, Ring 1.5 also provides the collapse mechanism associated with it. A final remark is necessary with regard to the influence of non-linear geometric effects on the load-carrying capacity, as it is known that such effects might reduce the capacity of some arches, particularly shallow or slender examples. In the present study, non-linear geometric effects were not considered of relevance as no shallow arches have been studied.

\subsection{Parametric analysis}

In order to obtain a deep insight into the most important parameters controlling their load-carrying capacity, a parametric analysis was performed on each of the reference bridges. The variables that most influence collapse load were identified by means of a previously published general parametric analysis [19]. The relevant variables considered here are geometrical and mechanical parameters of the arch and geometrical, mechanical and physical parameters of the fill:

- arch thickness $(t)$

- compressive strength of masonry $\left(f_{c}\right)$

- fill depth at the crown $(h)$

- mobilized earth pressure coefficient $\left(k_{\mathrm{p}}\right)$

- physical properties of the fill $(\gamma)$

The physical properties of the soil placed above the arch, here represented by the symbol $\gamma$, encompass its self-weight and internal friction angle. The variation in these properties directly implies the simultaneous and coherent variation of both parameters, as well as indirectly the variation of the earth pressure coefficient and fillbarrel friction angle [37].

The values adopted for parametric analysis are provided in Table 4. Besides the reference values, marked in bold, four additional physically-significant values were considered for each of the parameters listed above. Each cell represents an independent numerical analysis, as only one parameter was varied in each run. 


\subsection{Discussion of results}

An initial analysis of the results is given in Table 5, where the load factors for the four types of bridge are shown. The collapse mechanisms of bridges B and C are provided in Fig. 11 as an illustration of the mechanisms found. Load factors were computed using the reference parameter values and were higher than 7 in all cases, which seems to indicate that the reference bridges are structurally safe. The most unfavourable load position varies with the bridge considered. For short spans, the critical position of the central axle is at the bridge entrance for semi-shallow arches (bridge A) and around the 1/10 span for deep arches (bridge B). For medium spans, the critical location of the central axle is roughly at the $1 / 5$ span of the bridge for semi-shallow arches (bridge $\mathrm{C}$ ) and at about the $1 / 3$ span for deep arches (bridge D).

The results from the parametric analyses are summarized in Fig. 12, where load factor (denoted as $\mathrm{F}_{\mathrm{C}}$ ) is correlated with arch thickness, compressive strength, fill depth, mobilized earth pressure coefficient and physical properties, for the four reference bridges. The curves were normalized with respect to results and data of reference bridges, meaning that the point with coordinates $(1 ; 1)$ corresponds to the response of a reference bridge with reference data. This adopted representation highlights the sensitivity of bridges to each of the five parameters selected. It is clear that the increase of any parameter causes an increase in load factor for all four bridges, although in varying ways. Fig. 12 shows that the variation of arch thickness is very important to all bridges. Whilst variation of the mobilized earth pressure coefficient and of the physical properties of the fill affects deep bridges more greatly due to the effect of soil stabilization, variation infill depth has more of an effect on short span bridges. The variation effect of compressive strength is important mainly for very low values and shallow arches. In these cases, it is important to know the compressive strength in order to analyse the possibility of fragile failures, prior to the development of a ductile mechanism.

The grouping of results according to the type of bridge allows identifying beyond any doubt that arch thickness and physical properties of the soil are the most influential parameters on load factor value. This result is of major importance as the values assumed in Table 4 for these two parameters are likely to be found in reality. The importance of the other three parameters varies with bridge type. The mobilized earth pressure coefficient is most important for deep arches (B and D) due to the available fill depth and its stabilizing effect. For semi-shallow arches, fill depth is more important for short span bridges (A), while all three parameters have a similar importance for medium span bridges (C). Table 6 summarizes the importance of each parameter on load factor variation. 


\section{$5 \quad$ Ultimate load-carrying capacity of multi-span bridges}

Multi-span masonry arch bridges are often analysed as a series of separate single spans due to the presence of robust piers and the use of simpler numerical models. However, the ultimate load of a multi-span bridge modelled as such can sometimes be significantly lower than the value calculated by omitting adjacent spans.

\subsection{Numerical analysis}

With the aim of assessing the load factor of multi-span masonry arch bridges, four multi-span reference bridges are considered. Each of these additional reference bridges is composed of five equal spans (see Fig. 13), while their arches have the same characteristics as the single span reference examples (see section 3.2). The geometry of the piers was based on the geometrical survey, discussed in section 3.1. Width to span ratios of 0.50 and 0.30 were adopted for short span and medium span bridges, respectively. In terms of the height to width ratio, a value of 4 was considered for all piers (see Table 4). Although this is a higher value than that found in Fig. 7, Fig. 8 and Fig. 9, it acts as a method with which to include the probable uncertainties associated with the measurement of pier height.

Multi-span bridges were again modelled with Ring 1.5 software, in exactly the same way as for single span bridges. The number of pier blocks was not available in the literature and therefore an approximate block height of $0.60 \mathrm{~m}$ was adopted, which is the usual value found in bridges from the Minho region [26-27]. Moreover, the influence of the number of blocks on the variation in load factor, evaluated within a preliminary parametric analysis [19], was found to be low.

\subsection{Parametric analysis}

In order to characterize the sensibility of the ultimate load to pier geometry, four physically-significant values were considered for pier width and height in addition to the reference value, as illustrated in Table 4 . Within this section, only pier geometry was varied. It is expected that the characterization of how pier height influences load capacity may lead to an understanding of the importance of errors associated with the measurement of this geometrical parameter.

\subsection{Discussion of results}

Table 7 displays the load factors for the four multi-span reference bridges, calculated using the reference parameter values, while the collapse mechanism of bridge $\mathrm{C}$ is illustrated in Fig. 14. For all bridges the load factor is higher than 7, indicating that they are structurally safe. By comparing Table 5 with Table 7, it was found that multi-span bridges composed of deep arches (bridges B and D), modelled either as such or as a series of 
separate single spans, exhibit the same ultimate load. This is due to the occurrence of local collapse mechanisms (i.e. failure of a single arch). However, it is possible to identify a visible decrease in load factor associated with semi-shallow arch bridges (bridges A and C), namely $23 \%$ for short span and $11 \%$ for medium span bridges. Here, failure involves two adjacent spans (a global collapse mechanism). These results show that the calculation of load factors in multi-span masonry arch bridges using a single span is adequate only if a local failure mode is present. The most unfavourable load position (with reference to the central axle) depends on the slenderness of piers. For robust piers it is similar to the case of single span arches, while for slender piers it tends to approach the mid-span.

The results from the parametric analyses are presented in Fig. 15, where load factor is correlated with pier width and height. Within the normalization performed, the results obtained using reference parameter values are represented by the point with coordinates $(1 ; 1)$. An increase in pier width causes a subsequent increase in load factor up to a given threshold, defined as the change from global to local collapse mechanisms. Further increases in pier width are characterized by the failure of a single arch. Once arches were considered equal within a given reference multi-span bridge, load factor cannot increase further.

In terms of variation in pier height, Fig. 15(b) shows that its increase leads to a decrease in load factor, but only from a given threshold value onwards. This pattern, also visible in Fig. 15(a), is fully expressed only for bridge D. Within any given bridge, all local collapse mechanisms present the same load factor. Contrastingly, the load factor associated with global collapse mechanisms decreases with reduced pier width or increasing pier height. A threshold therefore delimits the transition between local and global collapse mechanisms and represents the geometric location of optimal load factor values, in the sense that it provides the location of the maximum load factors associated with minimal pier dimensions. It is possible to observe that the four reference bridges analysed are relatively close to these thresholds, which suggests a pier structural design close to its optimal value.

\section{Concluding remarks}

A collection of 59 roadway bridges located mainly in the adjacent geographical areas of northern Portugal and north-western Spain was considered. The sample is dominated by arches up to $10 \mathrm{~m}$ in span, typically with a relative depth higher than 0.25 , with $67 \%$ of bridges were built before the 15 th century. The geometrical ratios of the Portuguese and Spanish bridges analyzed are rather similar, thus indicating that their geographical proximity most probably resulted in the use of the same construction techniques and practical rules. 
The analysis of survey data indicates that many short span arches exhibit crown thickness and pier width values larger than the ones given by empirical rules. Short span arch bridges may have required minimum pier widths due to water stream and construction issues. In fact, while the width to span ratio is nearly constant for large spans, for short and medium spans the trend line found provides pier widths within a narrow range of values, where $3.0 \mathrm{~m}$ might be roughly assumed as an average value.

The numerical results showed that arch thickness and physical soil properties are the most influential parameters on load factor for single span bridges. However, the estimation of arch thickness is sometimes problematic because the external (visible) thickness may differ from the internal (effective) value. As for the multi-span bridges, it was found that all local collapse mechanisms present the same load factor, whereas for global collapse mechanisms the load factor decreases with decreasing pier width or increasing pier height. A threshold delimits the transition between global and local collapse mechanisms, at which optimal load factor values are found. Consequently, multi-span bridges can be assessed using a single span only if a local collapse mode is present.

For single and multi-span reference bridges, the load factor is always higher than 7 so the majority of bridges within the sample seem to be structurally safe with regard to applicable legislation. However, due to lack of maintenance many bridges show damage which might reduce their ultimate load-carrying capacities. A method of incorporating such features in numerical analysis may be to consider suitable reductions of key parameters, such as arch thickness, effective width or the compressive strength of masonry. Nevertheless, correlating the existing damage level with a decrease in other properties is a hard task that requires further research - namely a comprehensive in-situ damage survey. Finally, this work has shown that geometrical data combined with suitable numerical tools can provide a good insight into the safety of large samples of masonry arch bridges located within a common geographic area.

\section{Acknowledgements}

The authors would like to acknowledge the useful contributions of Dr. Paulo Amaral, Prof. Michela Monaco and

Prof. Duran Fuentes to this work. Authors are also very grateful to the anonymous reviewers whose comments led to an important improvement of the paper.

\section{References}

[1] Kurrer K.-E., Kahlow A. Arch and vault from 1800 to 1864. Second International Conference on Arch Bridges, Venice, Italy, 1998, 37-42. 
[2] Proske D., van Gelder P. Safety of historical stone arch bridges. Springer, 2009.

[3] Fuentes M.D. An endeavour to identify Roman bridges built in former Hispania. First International Congress on Construction History, Madrid, Spain, 2003, 775-786.

[4] Pippard A.J.S., Tranter E., Chitty L.C. The mechanics of the voussoir arch. Journal of the Institution of Civil Engineers, 4, 1936, 281-306.

[5] Heyman J. The stone skeleton. International Journal of Solids and Structures, 2, 1966, 249-279.

[6] Livesley R.K. Limit analysis of structures formed from rigid blocks. International Journal for Numerical Methods in Engineering, 12, 1978, 1853-1871.

[7] Gilbert M., Melbourne C. Rigid-block analysis of masonry structures. The Structural Engineer, 72, 1994, 356-361.

[8] Brencich A., De Francesco U. Assessment of multispan masonry arch bridges. I: Simplified approach. Journal of Bridge Engineering, 9(6), 2004, 582-590.

[9] Harvey B., Ross K., Orban Z. A simple, first filter assessment for arch bridges. Fifth International Conference on Arch Bridges, Madeira, Portugal, 2007, 275-279.

[10] Gilbert M. Limit analysis applied to masonry arch bridges: state-of-the-art and recent developments. Fifth International Conference on Arch Bridges, Madeira, Portugal, 2007, 13-28.

[11] Orbán Z., Gutermann M. Assessment of masonry arch railway bridges using non-destructive in-situ testing methods. Engineering Structures, 31(10), 2009, 2287-2298.

[12] Nunes A.J. Ancient bridges from Bragança municipality (in Portuguese). Mirandela, Portugal, 1997.

[13] Carita H. Bridges in Portugal (in Portuguese). Secil, 1998.

[14] Luís G., Santos S. Ancient bridges over Ave and Vizela rivers (in Portuguese). Internal report, University of Minho, Guimarães, Portugal, 1999.

[15] Costa C. Behaviour analysis of the Lagoncinha bridge under traffic load (in Portuguese). MSc thesis, FEUP, Porto, Portugal, 2002.

[16] Rodrigues N. Rehabilitation of historical masonry bridges (in Portuguese). MSc thesis, IST, Lisbon, Portugal, 2008.

[17] Rouxinol G. Modelling and structural assessment of masonry arch bridges (in Portuguese). PhD thesis, FCTUC, Coimbra, Portugal, 2008.

[18] Ferreira M.R. Masonry bridges in Portugal: damage, rehabilitation and management (in Portuguese). MSc thesis, IST, Lisbon, Portugal, 2008.

[19] Lemos C. Masonry arch bridges: geometrical issues and load capacity (in Portuguese), MSc thesis, University of Minho, Guimarães, Portugal, 2009.

[20] Corradi M. Geometry and strength of materials in the construction of bridges during the 19th century (in French). Third International Conference on Arch Bridges, Paris, France, 2001, 69-76.

[21] Albenga G. Lessons on bridges (in Italian). Vol. 1, Torino, 1930.

[22] Campanella G. Masonry bridges for engineers (in Italian). Biblioteca Tecnica Internazionale, Milano, 1928.

[23] Brencich A., Morbiducci R. Masonry arches: historical rules and modern mechanics. International Journal of Architectural Heritage, 1(2), 2007, 165-189.

[24] Fuentes M.D. The construction of Roman bridges in Hispania (in Spanish). Xunta de Galicia, 2005. 
[25] IGESPAR, www.monumentos.pt (accessed in November 2008).

[26] Oliveira D.V., Lourenço P.B. Structural stability and strengthening design of the Donim Bridge. Part II: Strengthening design (in Portuguese). Internal report, University of Minho, Guimarães, Portugal, 2004.

[27] Oliveira D.V., Lourenço P.B. Strengthening design of Negrelos Bridge (in Portuguese). Internal report, University of Minho, Guimarães, Portugal, 2004.

[28] Brencich A., De Francesco U. Assessment of Multispan Masonry Arch Bridges. II: Examples and Applications. Journal of Bridge Engineering, 9(6), 2004, 591-598.

[29] Limitstate Ring2.0: theory \& modelling guide (version 2.0j), 2008.

[30] Fernandes F.M. Evaluation of two novel NDT techniques: micro-drilling of clay bricks and ground penetrating radar in masonry. PhD dissertation, University of Minho, Guimarães, Portugal, 2006 (available at www.civil.uminho.pt/masonry).

[31] Arias P., Armesto J., Di-Capua D., Gonzalez-Drigo R., Lorenzo H., Perez-Gracia V. Digital photogrammetry, GPR and computational analysis of structural damages in a mediaeval bridge. Engineering Failure Analysis, 14, 2007, 1444-1457.

[32] Lourenço P.B. Computations on historic masonry structures. Prog. Struct. Eng. Mater., 4, 2002, 301-319.

[33] Orduña A., Lourenço P.B. Cap model for limit analysis and strengthening of masonry structures. J. Struct. Eng., ASCE, 129(10), 2003, 1367-1375.

[34] Gilbert M., Ahmed H.M. Developments to the Ring masonry arch bridge analysis software. Fourth International Conference on Arch Bridges, Barcelona, Spain, 2004, 263-272.

[35] Gilbert M.: RING Theory and modelling guide. Computational limit analysis and design unit, University of Sheffield, UK, 2005.

[36] RSA Safety and load code for buildings and bridge structures (in Portuguese). Decreto-Lei N. ${ }^{\circ}$ 235/83, Imprensa Nacional, Casa da Moeda, Lisboa, Portugal, 1983.

[37] Smith C., Gilbert M., Callaway P. Geotechnical issues in the analysis of masonry arch bridges. Fourth International Conference on Arch Bridges, Barcelona, Spain, 2004, 343-352. 
Table 1. Historical empirical rules for crown arch thickness.

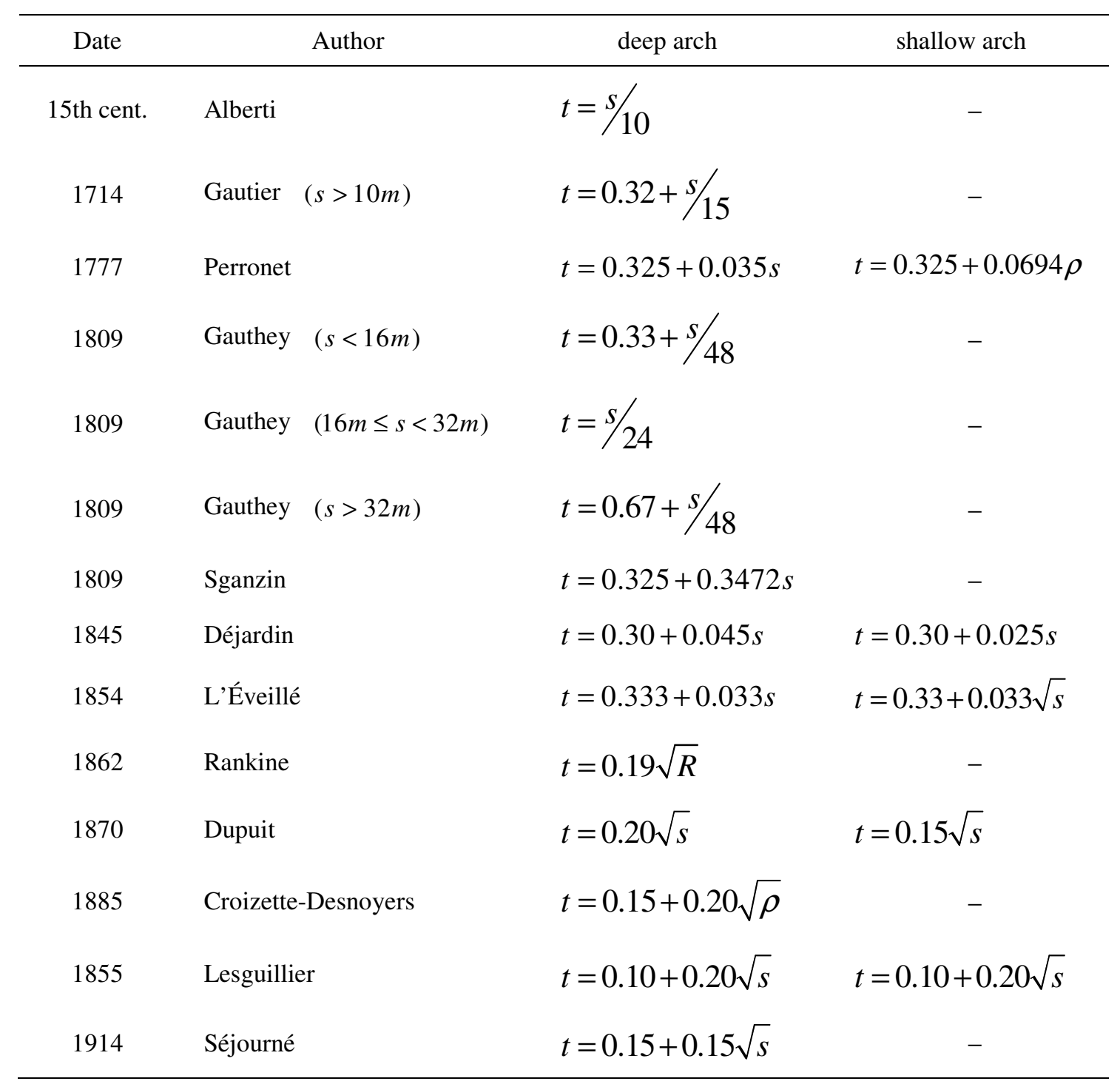

$s:$ span; $R$ : radius of the circle passing through the crown and intrados springing; $\rho$ : curvature radius 
Table 2. Single span reference bridges derived from the sample population.

\begin{tabular}{lll}
\hline & semi-shallow arch & deep arch \\
\hline \multirow{3}{*}{ short span } & $r=5.0 \mathrm{~m}$ & $s=5.0 \mathrm{~m}$ \\
& $t=0.50 \mathrm{~m}$ & $r / s=0.50$ \\
& (bridge A) & $t=0.60 \mathrm{~m}$ \\
medium span & $s=10 \mathrm{~m}$ & (bridge B) \\
& $r / s=0.30$ & $s=10 \mathrm{~m}$ \\
& $t=0.70 \mathrm{~m}$ & $r / s=0.50$ \\
& $($ bridge C) & $t=1.0 \mathrm{~m}$ \\
\end{tabular}


Table 3. Material and mechanical properties adopted for the reference bridges.

\begin{tabular}{ll}
\hline Stone masonry & Fill material \\
\hline self-weight $=25 \mathrm{kN} / \mathrm{m}^{3}$ & self-weight $=20 \mathrm{kN} / \mathrm{m}^{3}$ \\
friction angle $=30^{\circ}$ & fill friction angle $=30^{\circ}$ \\
compressive strength $=5 \mathrm{MPa}$ & fill-barrel friction angle $=20^{\circ}$ \\
\hline
\end{tabular}


Table 4. Values adopted for parametric analysis (reference values marked in bold).

\begin{tabular}{|c|c|c|c|c|c|c|c|c|}
\hline & \multirow{2}{*}{$\frac{\text { Parameter }}{\text { fill properties }(\gamma)}$} & \multicolumn{2}{|r|}{ Unit } & \multicolumn{5}{|c|}{ Parametric variation } \\
\hline \multirow{3}{*}{ 妵 } & & & $\left({ }^{\mathrm{o}} ; \mathrm{kN} / \mathrm{m}^{3}\right)$ & $(20 ; 18)$ & $(25 ; 19)$ & $(30 ; 20)$ & $(35 ; 21)$ & $(40 ; 22)$ \\
\hline & fill depth $(h)$ & & {$[\mathrm{m}]$} & 0.0 & 0.2 & 0.4 & 0.6 & 0.8 \\
\hline & $\begin{array}{l}\text { mobilized earth press } \\
\text { coefficient }\left(k_{\mathrm{p}}\right)\end{array}$ & sure & - & 0.30 & 0.40 & 0.50 & 0.75 & 1.00 \\
\hline \multirow{5}{*}{ 苞 } & compressive strength & $\left(f_{\mathrm{c}}\right)$ & {$[\mathrm{MPa}]$} & 3 & 4 & 5 & 10 & 20 \\
\hline & \multirow{4}{*}{ arch thickness $(t)$} & A & \multirow{4}{*}[\mathrm{m}]{} & 0.35 & 0.42 & 0.50 & 0.58 & 0.65 \\
\hline & & $\mathrm{B}$ & & 0.40 & 0.50 & 0.60 & 0.70 & 0.80 \\
\hline & & $\mathrm{C}$ & & 0.50 & 0.60 & 0.70 & 0.80 & 0.90 \\
\hline & & $\mathrm{D}$ & & 0.70 & 0.85 & 1.00 & 1.15 & 1.30 \\
\hline \multirow{8}{*}{$\stackrel{\infty}{\omega}$} & \multirow{4}{*}{ width of piers $(W)$} & $\mathrm{A}$ & \multirow{4}{*}[\mathrm{m}]{} & 1.75 & 2.5 & 3.25 & 4.00 & 4.75 \\
\hline & & $\mathrm{B}$ & & 1.75 & 2.5 & 3.25 & 4.00 & 4.75 \\
\hline & & $\mathrm{C}$ & & 2.00 & 3.00 & 4.00 & 5.00 & 6.00 \\
\hline & & $\mathrm{D}$ & & 2.00 & 3.00 & 4.00 & 5.00 & 6.00 \\
\hline & \multirow{4}{*}{ height of piers $(H)$} & $\mathrm{A}$ & \multirow{4}{*}[\mathrm{m}]{} & 7.0 & 10.0 & 13.0 & 16.0 & 19.0 \\
\hline & & $\mathrm{B}$ & & 7.0 & 10.0 & 13.0 & 16.0 & 19.0 \\
\hline & & $\mathrm{C}$ & & 9.0 & 12.0 & 15.0 & 18.0 & 21.0 \\
\hline & & $\mathrm{D}$ & & 9.0 & 12.0 & 15.0 & 18.0 & 21.0 \\
\hline
\end{tabular}


Table 5. Load factors for the four single span reference bridges considered.

\begin{tabular}{ccc}
\hline & semi-shallow arch & deep arch \\
\hline short span & 10.6 & 7.54 \\
medium span & 8.26 & 9.51 \\
\hline
\end{tabular}


Table 6. Most relevant parameters affecting load factor value (in descending order).

\begin{tabular}{ccc}
\hline & semi-shallow & deep \\
\hline \multirow{3}{*}{ short span } & $t$ & $\gamma$ \\
& $\gamma$ & $t$ \\
& $h$ & $k_{\mathrm{p}}$ \\
\hline \multirow{3}{*}{ medium span } & $t$ & $\gamma$ \\
& $\gamma$ & $t$ \\
\hline
\end{tabular}


Table 7. Load factors for the four multi-span reference bridges considered.

\begin{tabular}{ccc}
\hline & semi-shallow arch & deep arch \\
\hline short span & 8.11 & 7.54 \\
medium span & 7.33 & 9.51 \\
\hline
\end{tabular}




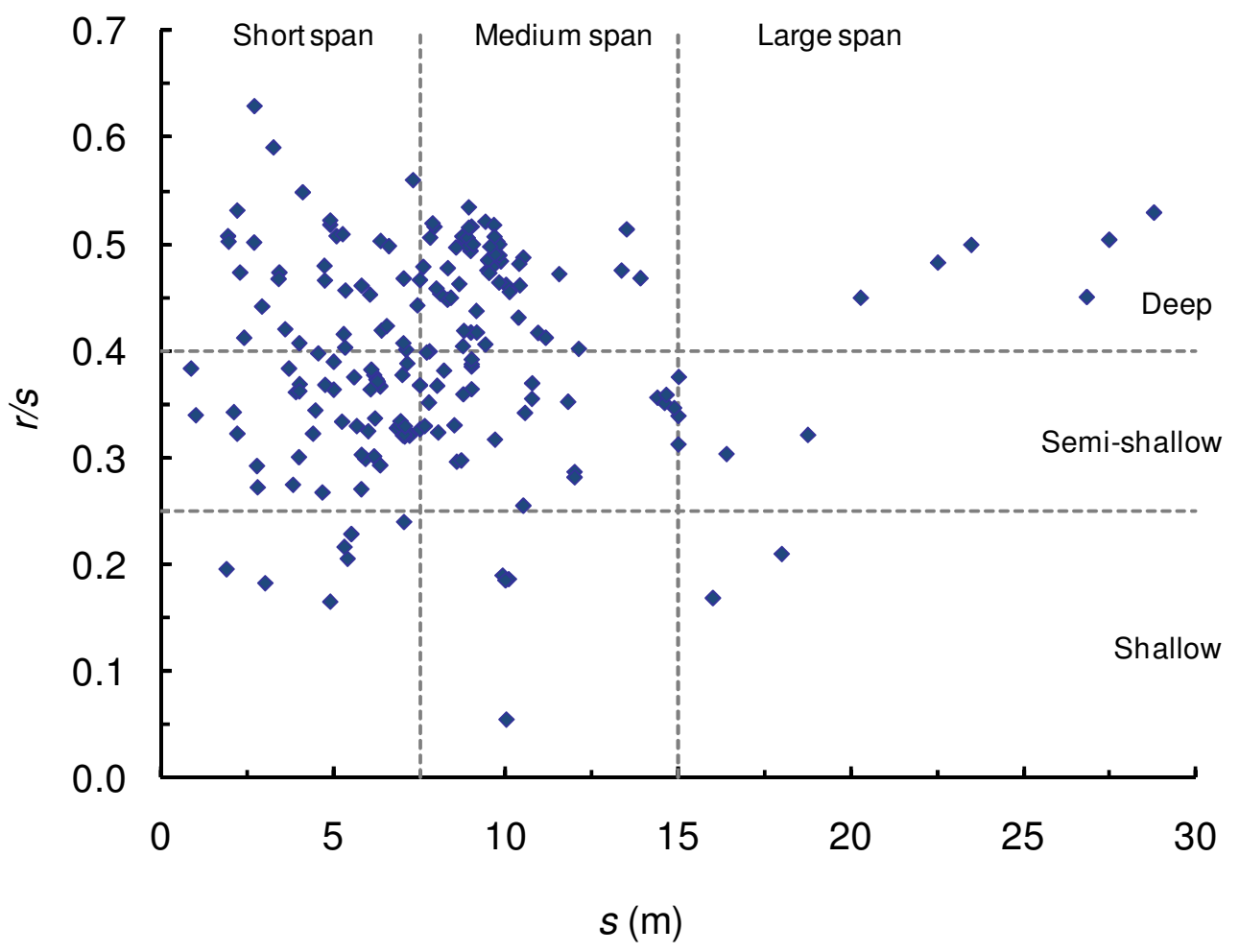

Fig. 1. Relationship between span $(s)$ and rise to span ratio $(r / s)$. 


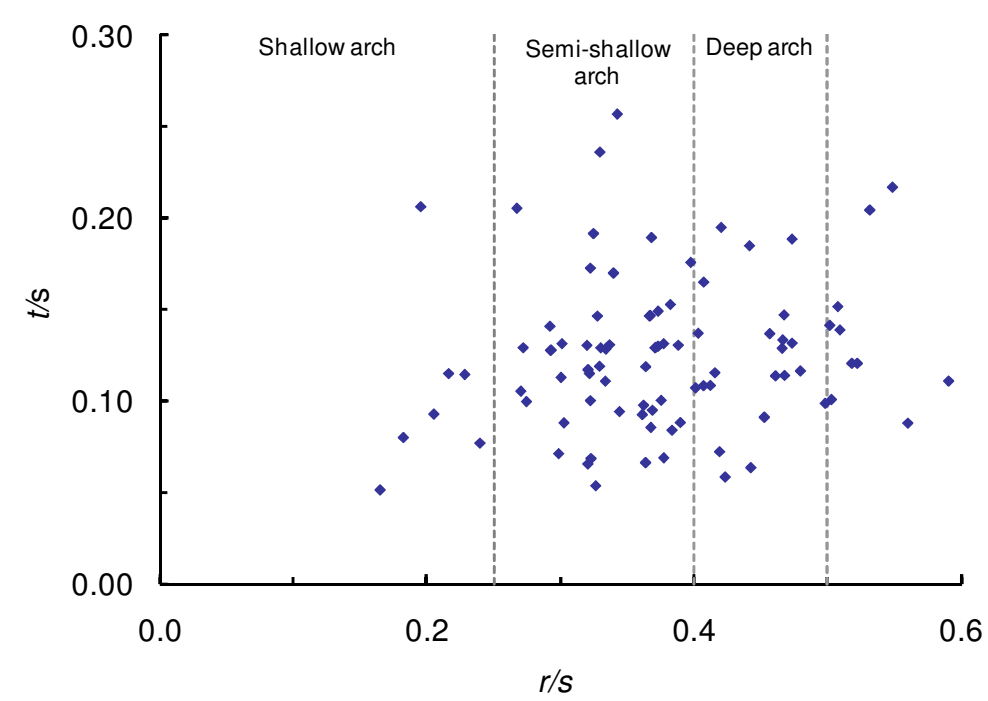

(a)

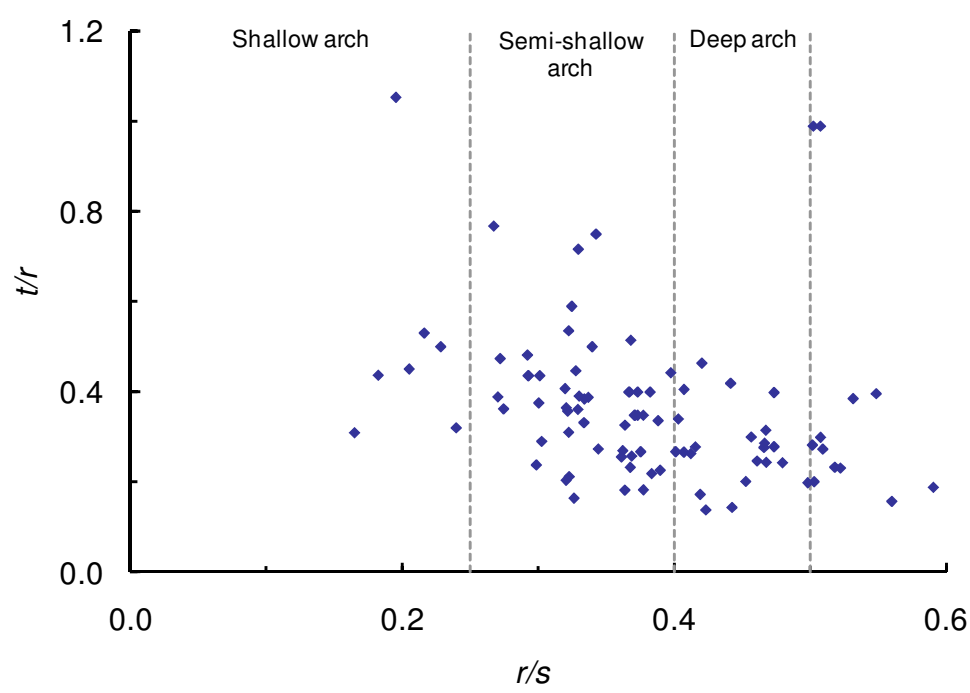

(b)

Fig. 2. Short span arches: non-dimensional relationships between relative depth $(r / s)$ and: (a) thickness to span ratio $(t / s)$; (b) thickness to rise ratio $(t / r)$. 


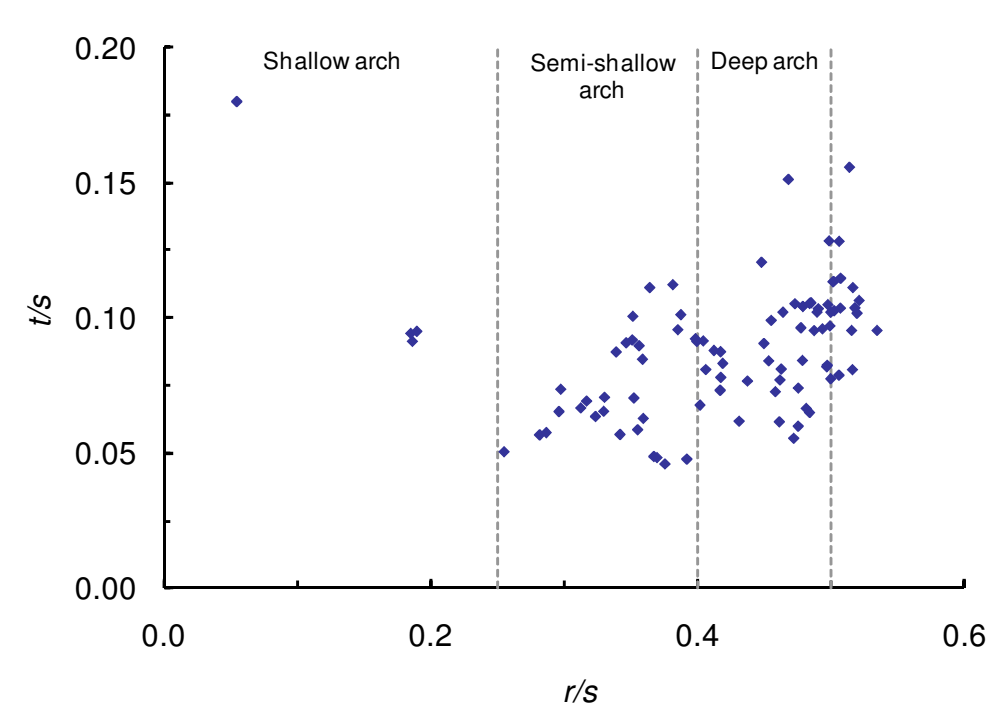

(a)

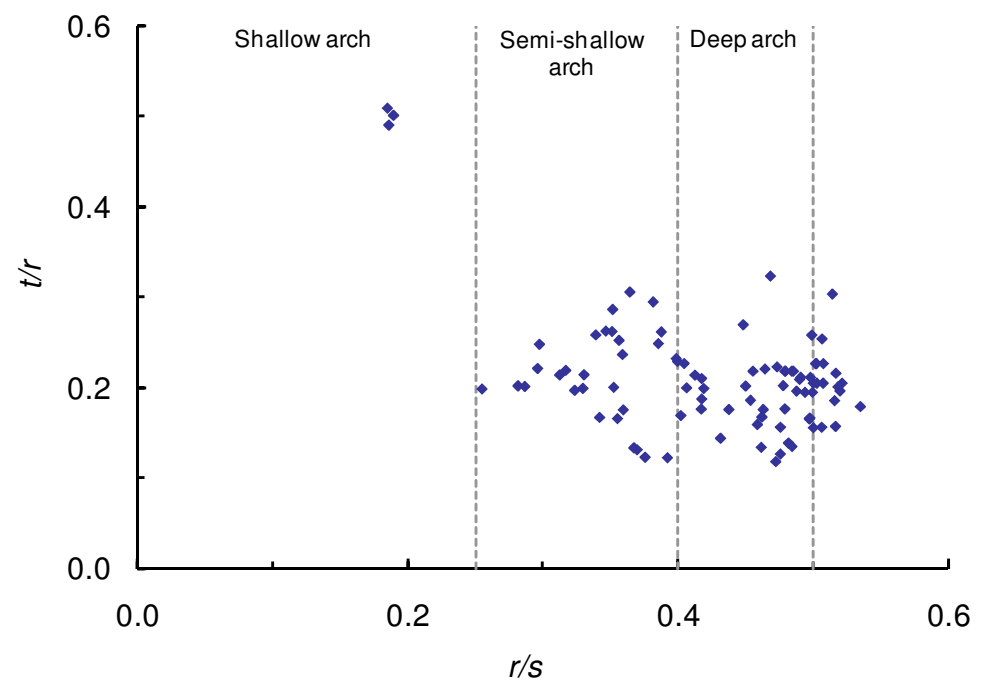

(b)

Fig. 3. Medium span arches: non-dimensional relationships between relative depth $(r / s)$ and: (a) thickness to span ratio $(t / s)$; (b) thickness to rise ratio $(t / r)$. 


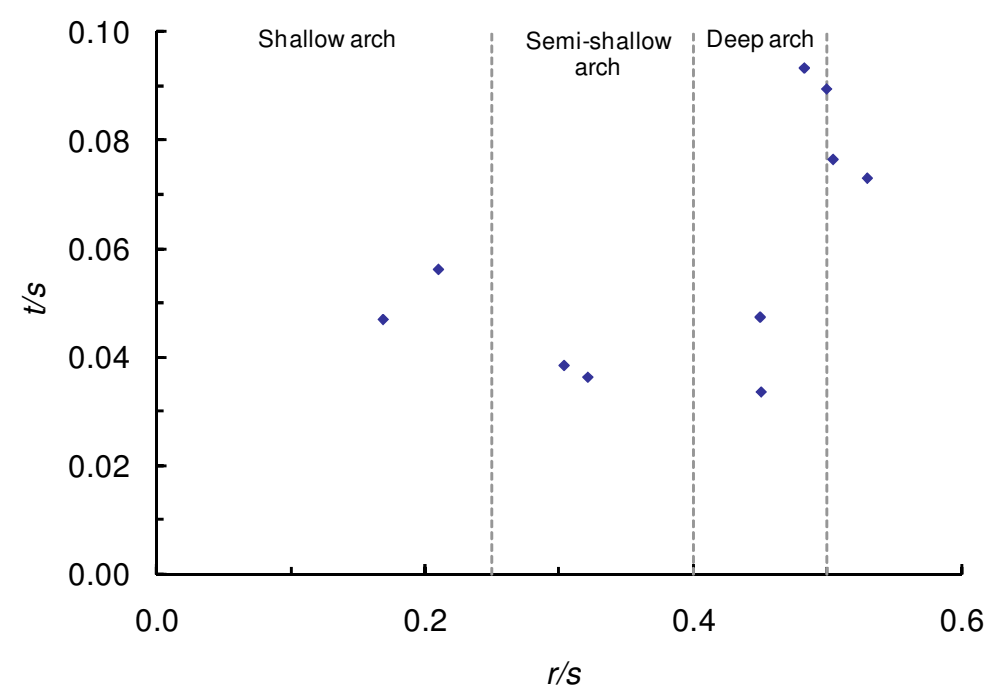

(a)

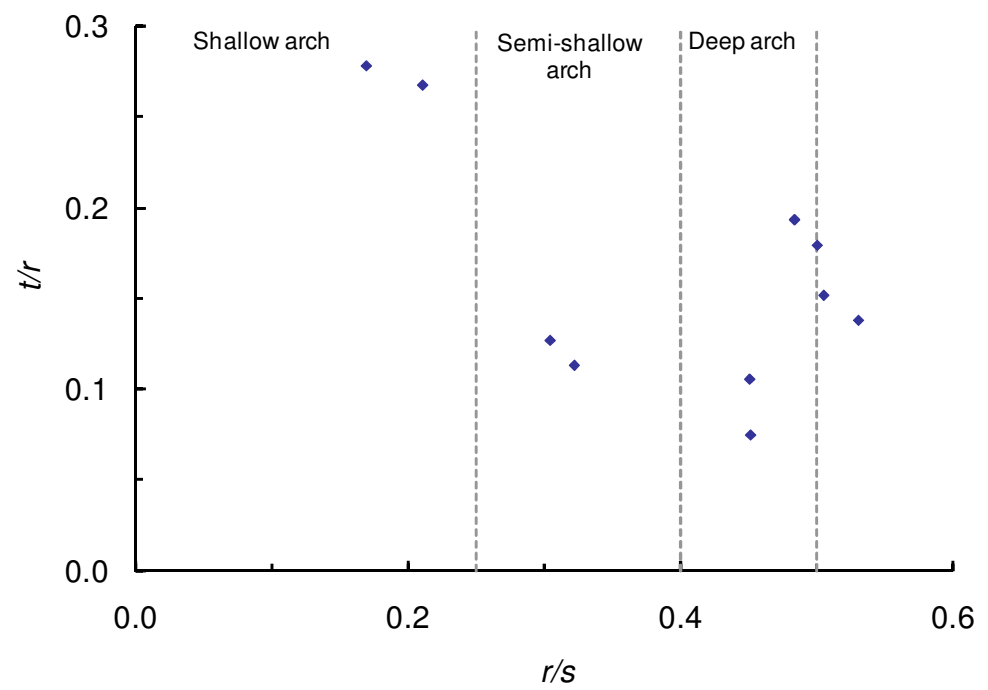

(b)

Fig. 4. Large span arches: non-dimensional relationships between relative depth $(r / s)$ and: (a) thickness to span ratio $(t / s)$; (b) thickness to rise ratio $(t / r)$. 


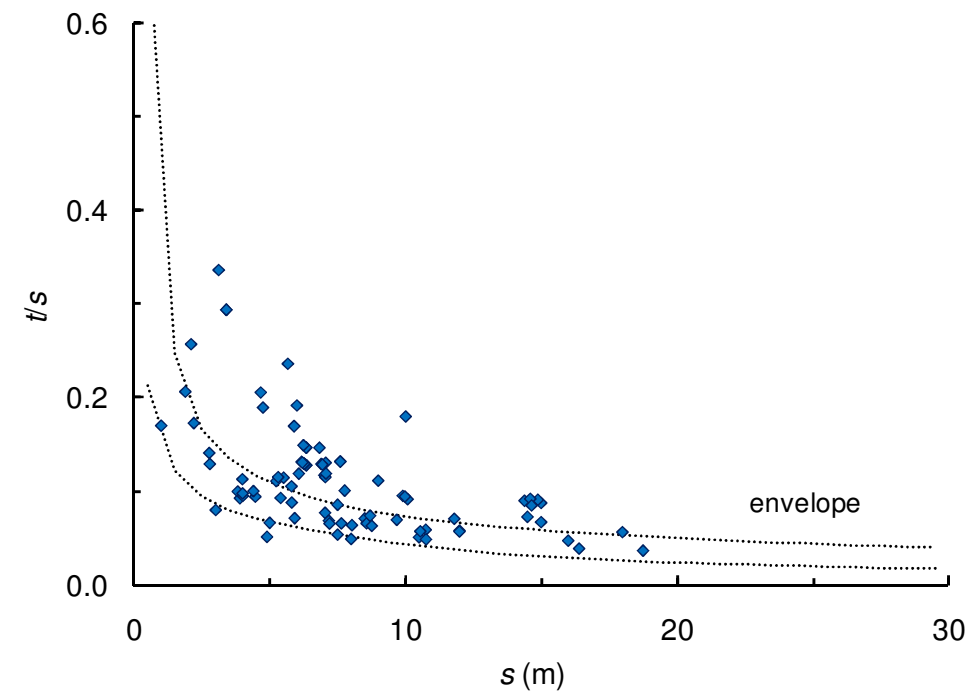

(a)

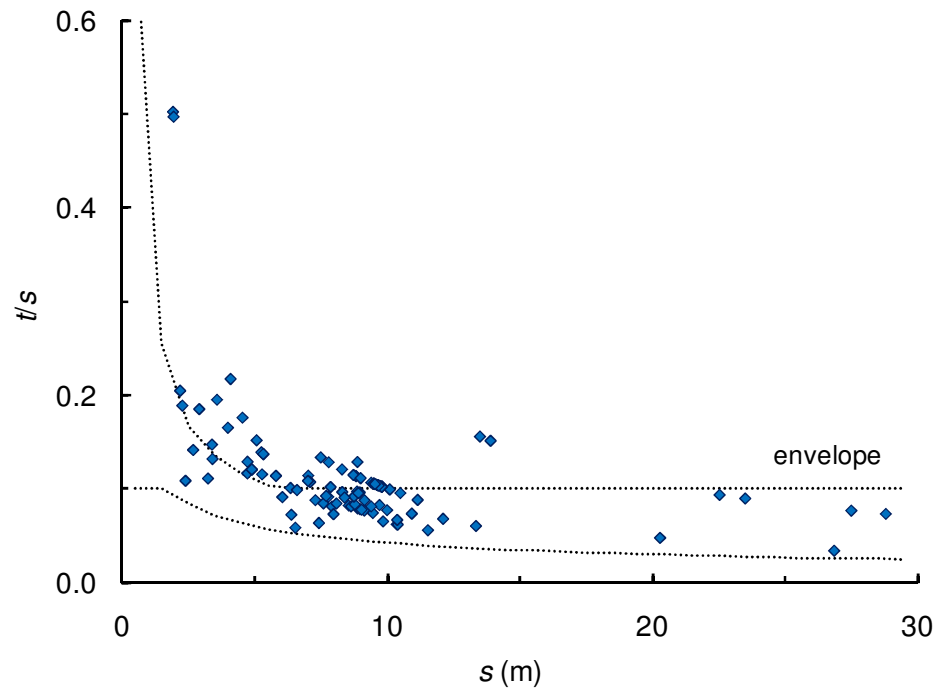

(b)

Fig. 5. Comparison between empirical envelope and survey data in terms of span $(s)$ vs. thickness to span ratio ( $t / s)$, for: (a) shallow and semi-shallow arches; (b) deep arches (also see Table 1). 


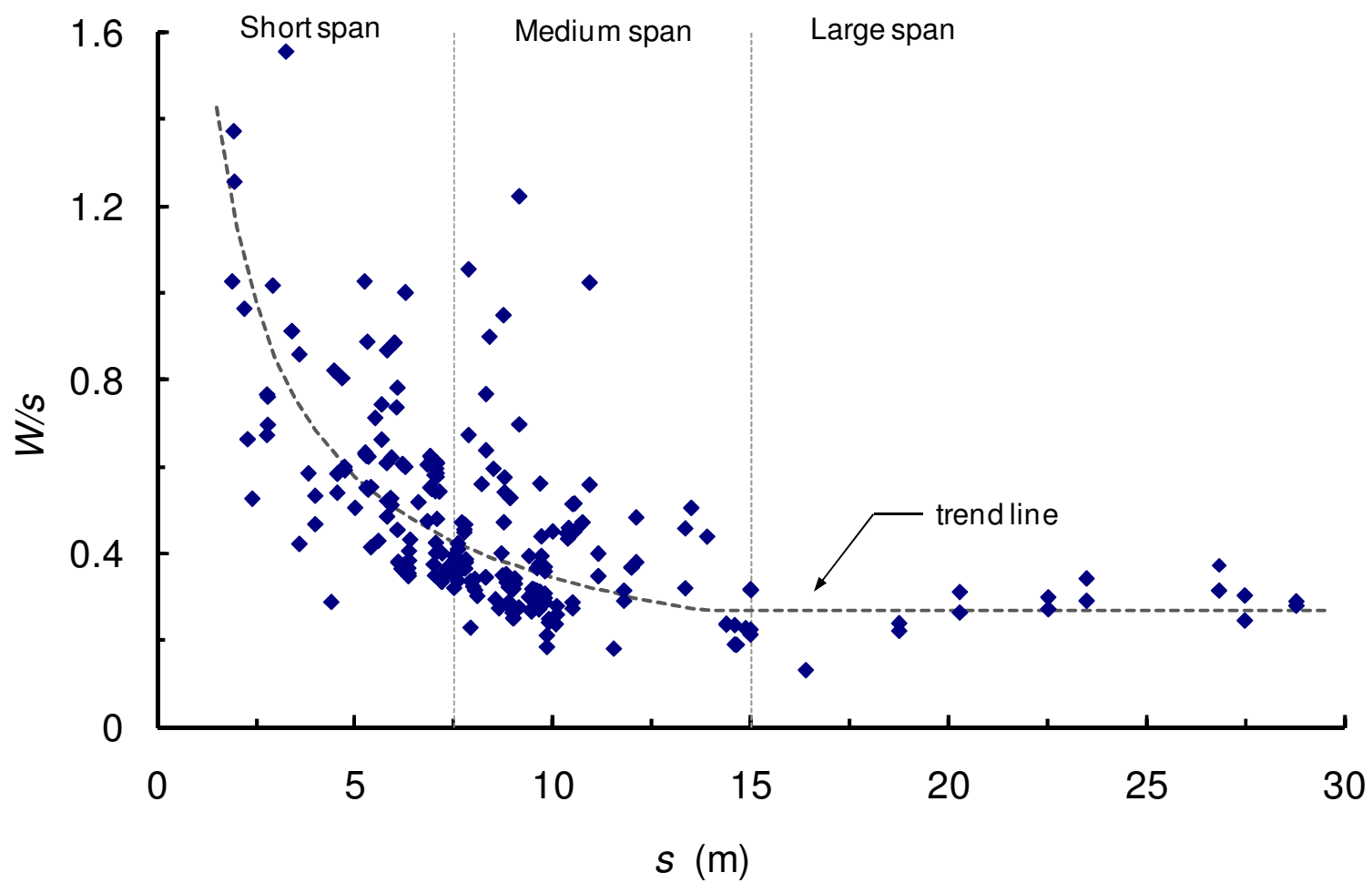

Fig. 6. Relationship between span $(s)$ and width to span ratio $(W / s)$. 


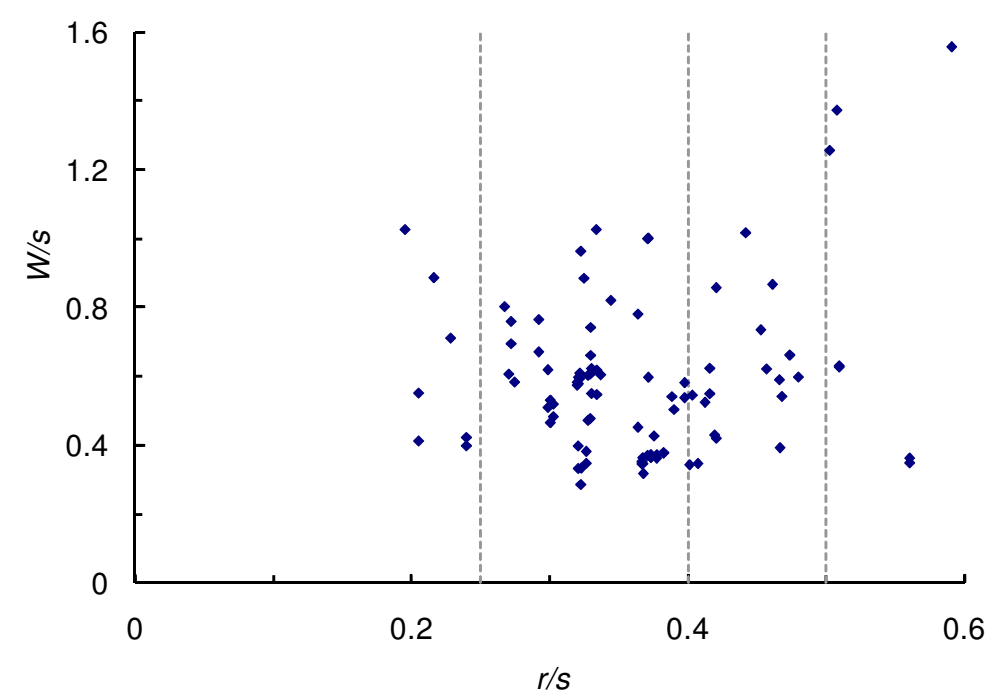

(a)

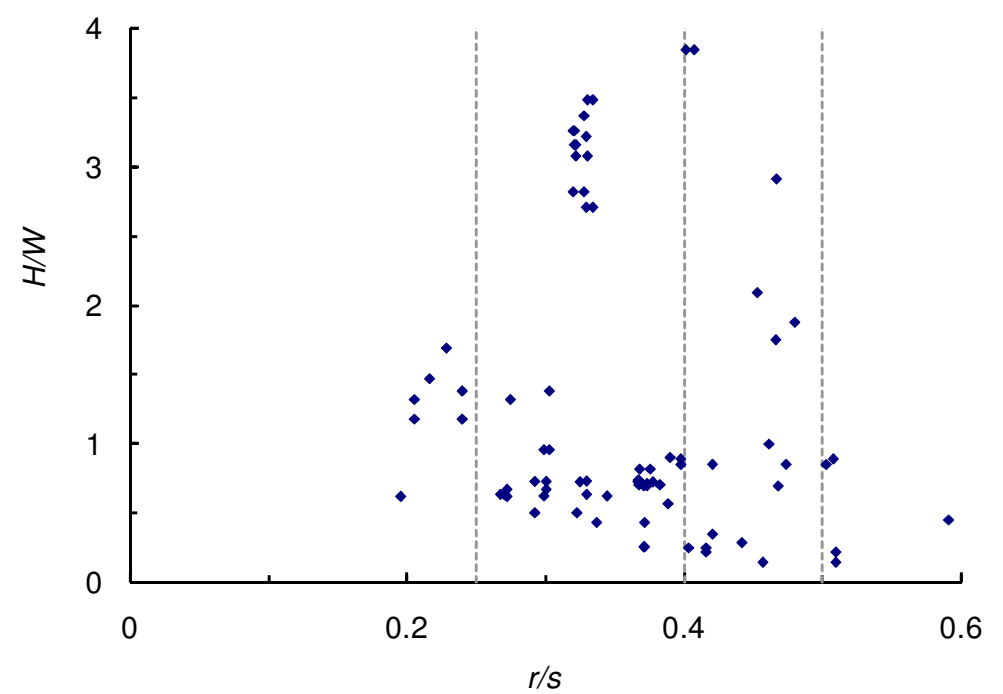

(b)

Fig. 7. Short span arches: non-dimensional relationships between relative depth $(r / s)$ and: (a) pier width to span ratio (W/s); (b) pier height to width ratio $(H / W)$. 


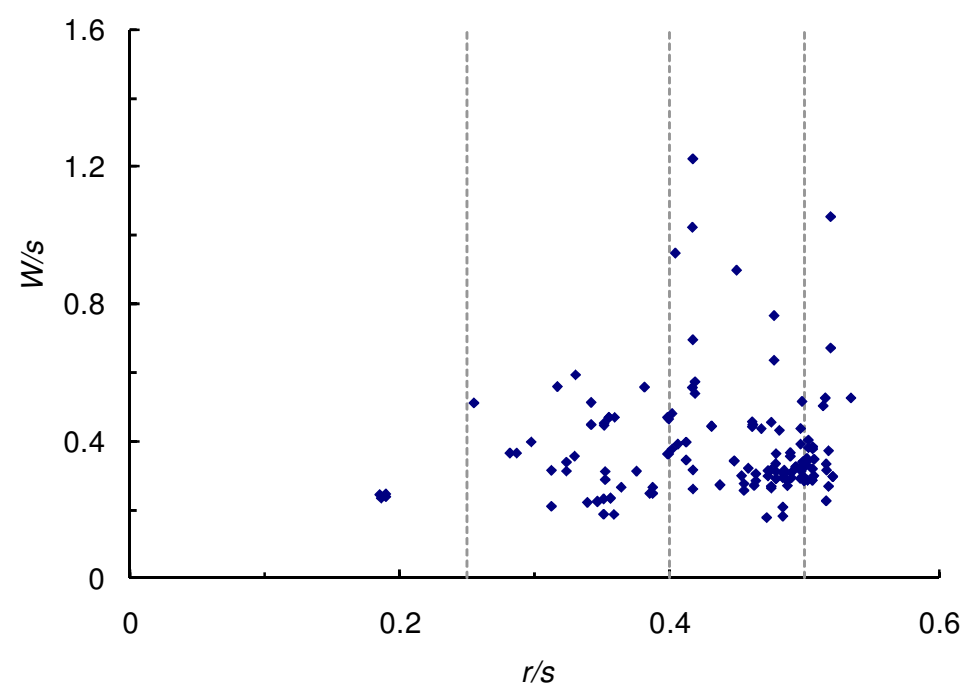

(a)

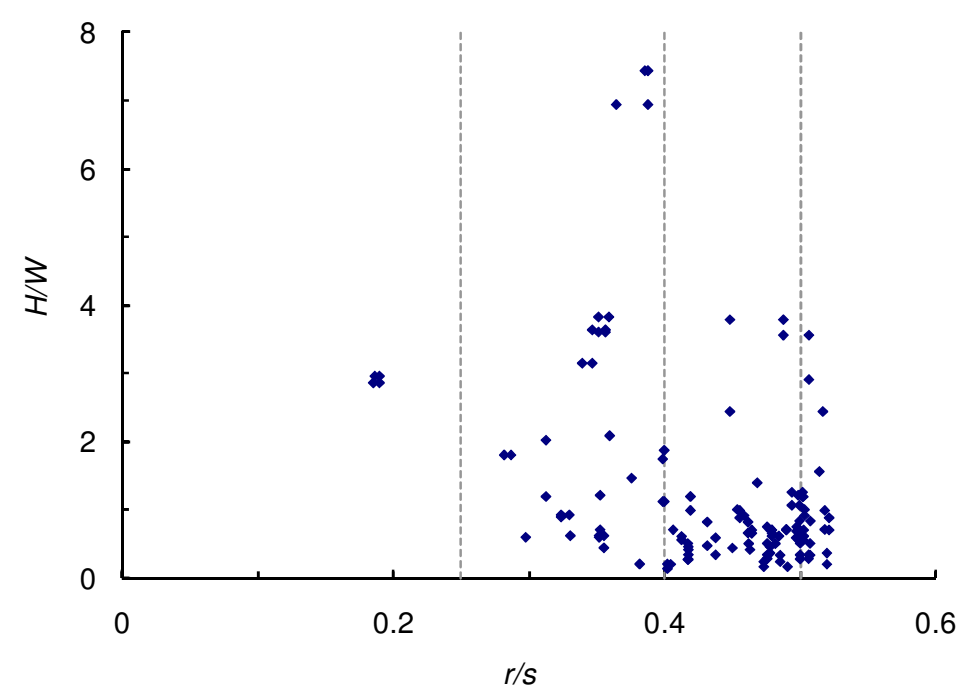

(b)

Fig. 8. Medium span arches: non-dimensional relationships between relative depth $(r / s)$ and: (a) pier width to span ratio (W/s); (b) pier height to width ratio $(H / W)$. 


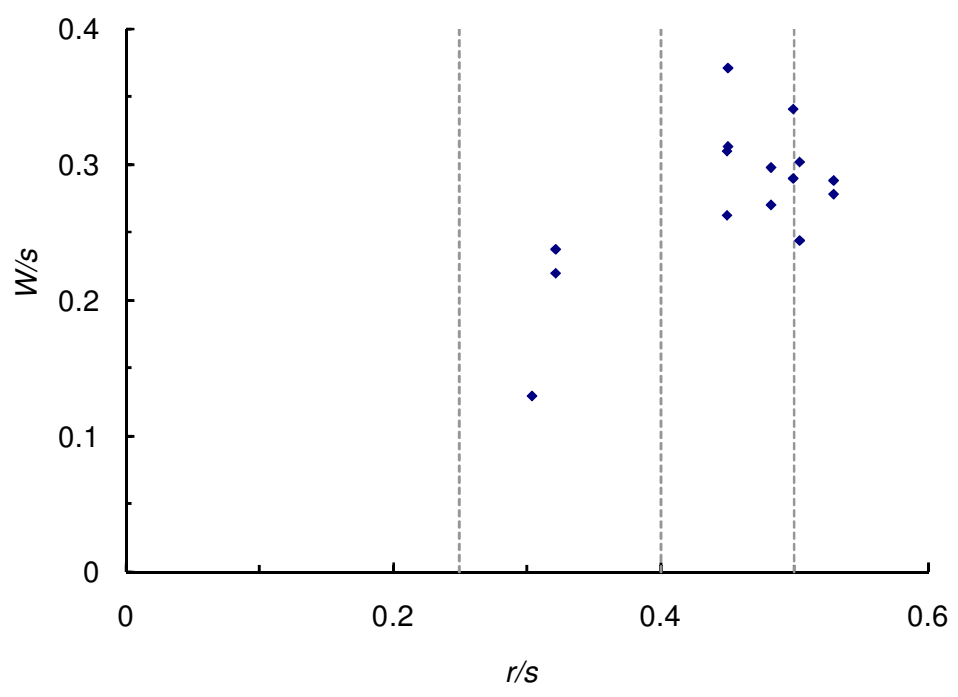

(a)

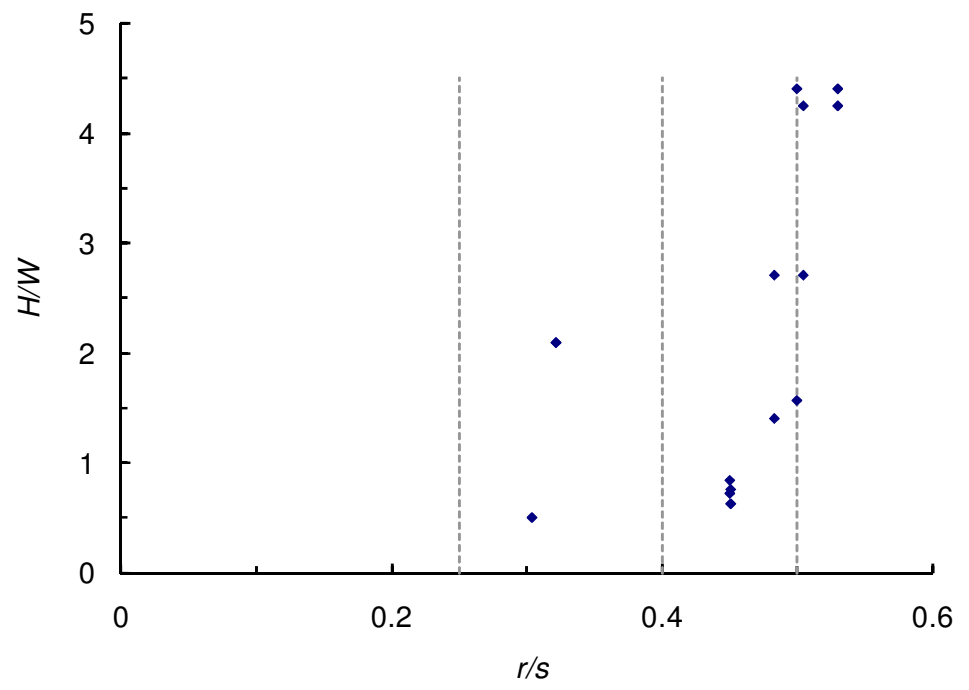

(b)

Fig. 9. Large span arches: non-dimensional relationships between relative depth $(r / s)$ and: (a) pier width to span ratio (W/s); (b) pier height to width ratio $(H / W)$. 


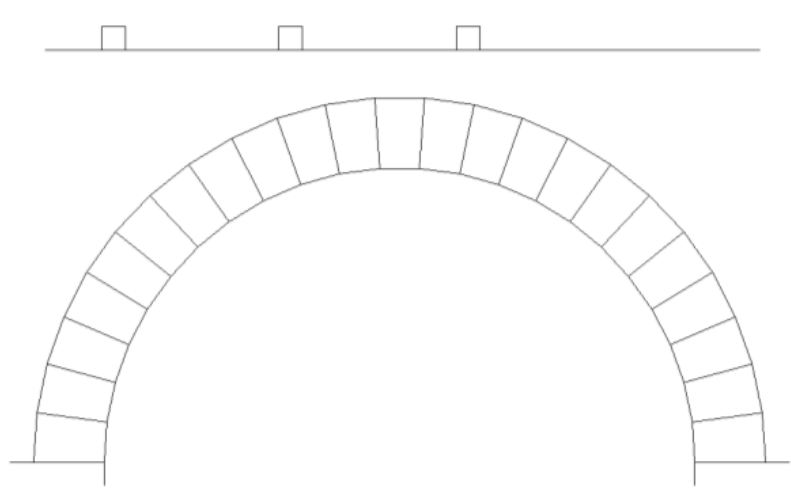

(a)

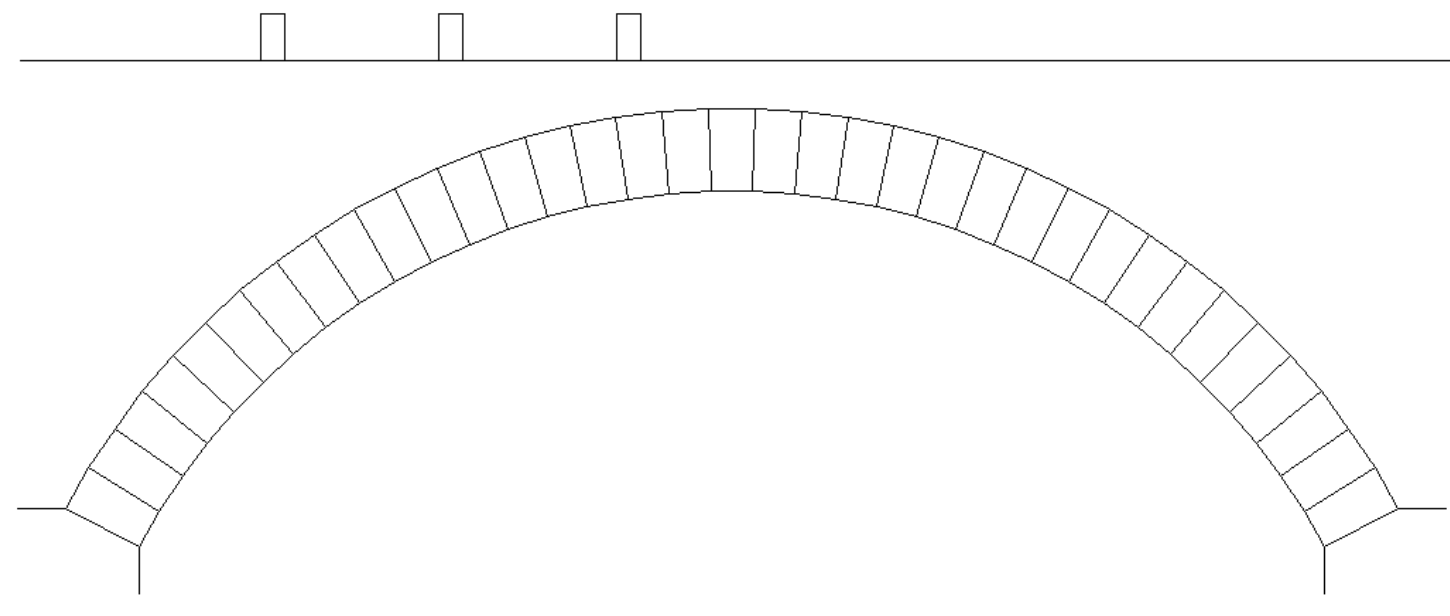

(b)

Fig. 10. Elevation view of single span reference bridges: (a) bridge B; (b) bridge $C$. 
$\square$

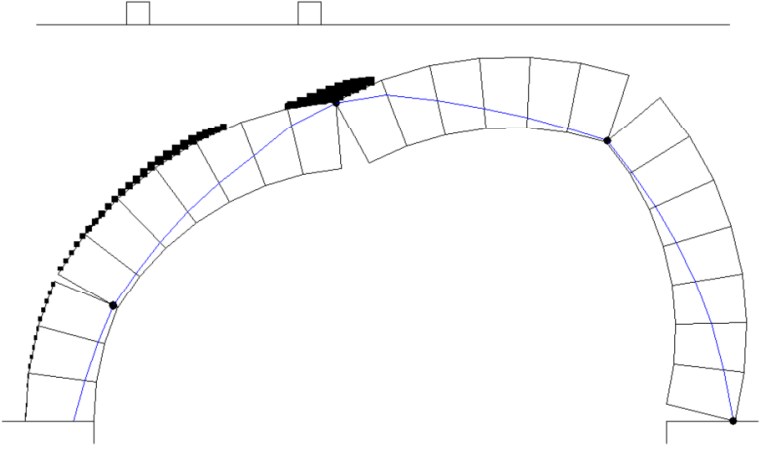

(a)

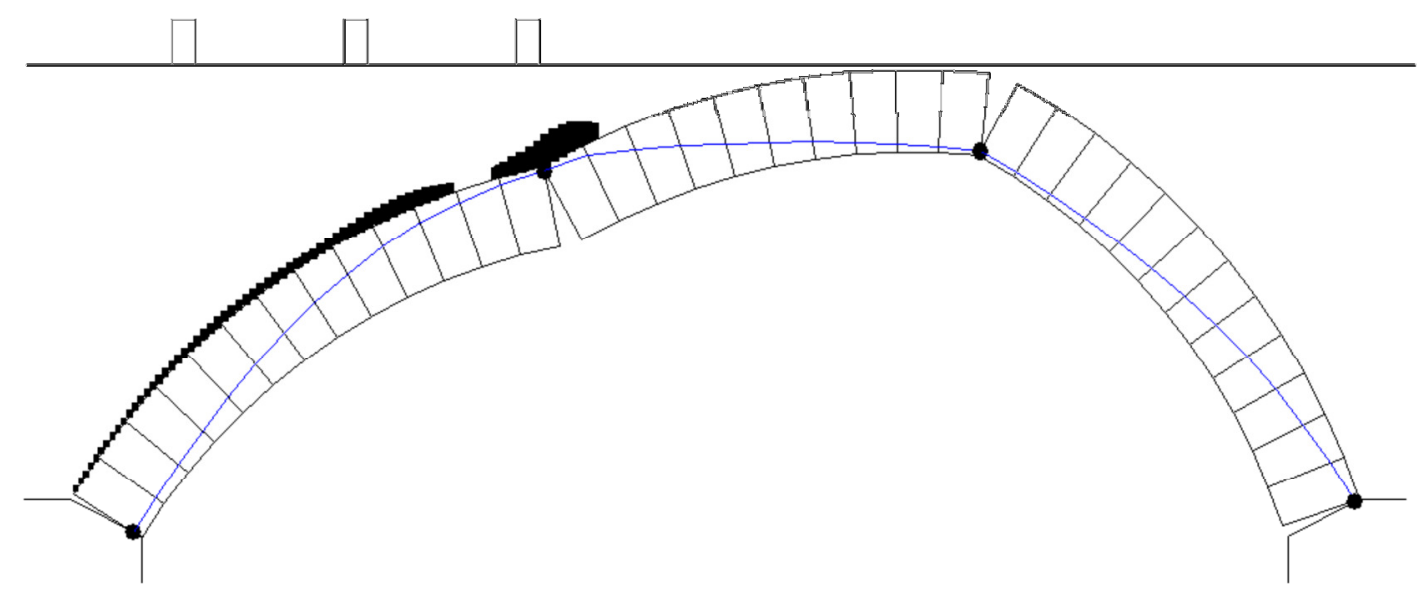

(b)

Fig. 11. Collapse mechanisms of single span reference bridges: (a) bridge $B$; (b) bridge $C$. 


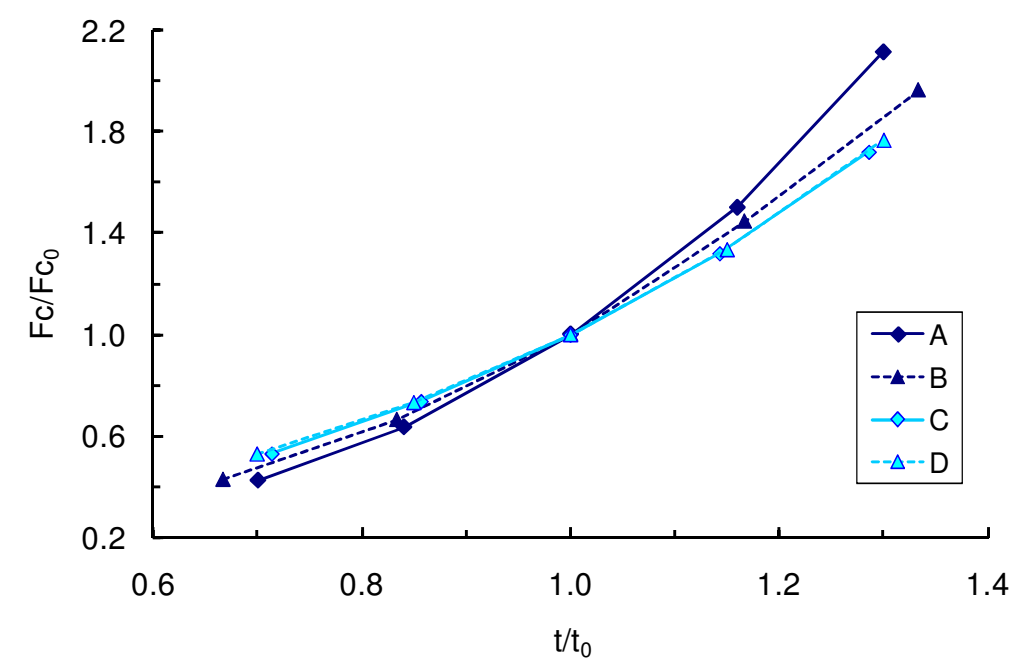

(a)

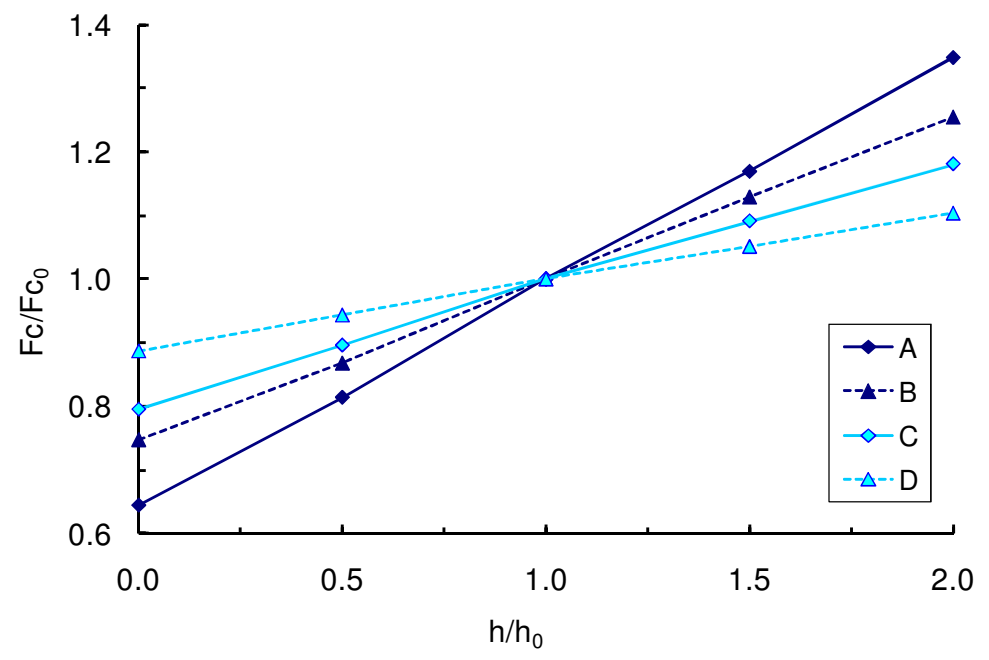

(c)

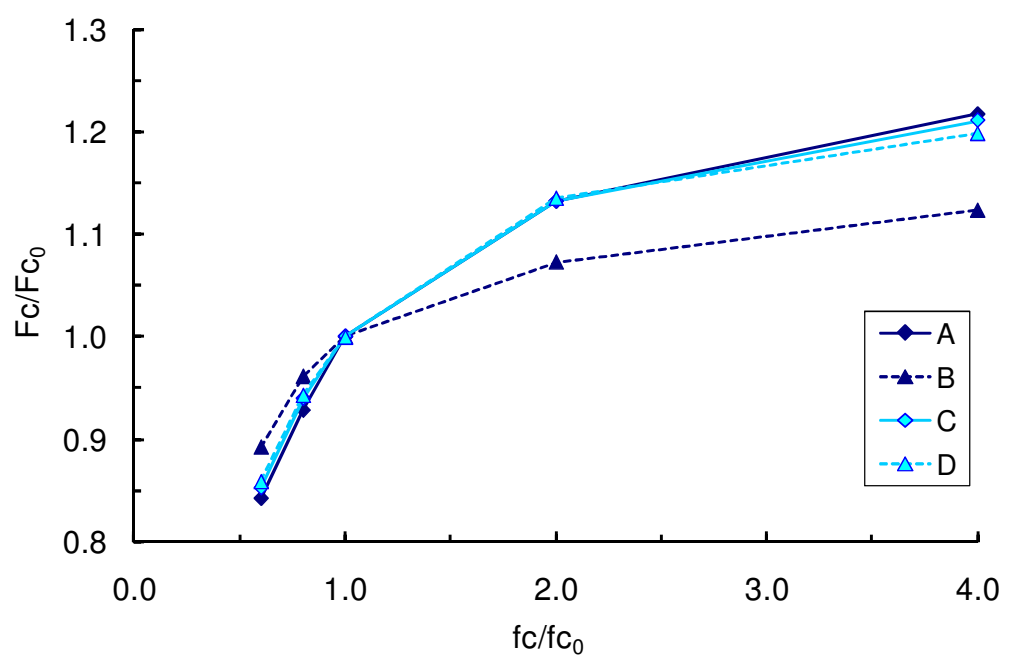

(b)

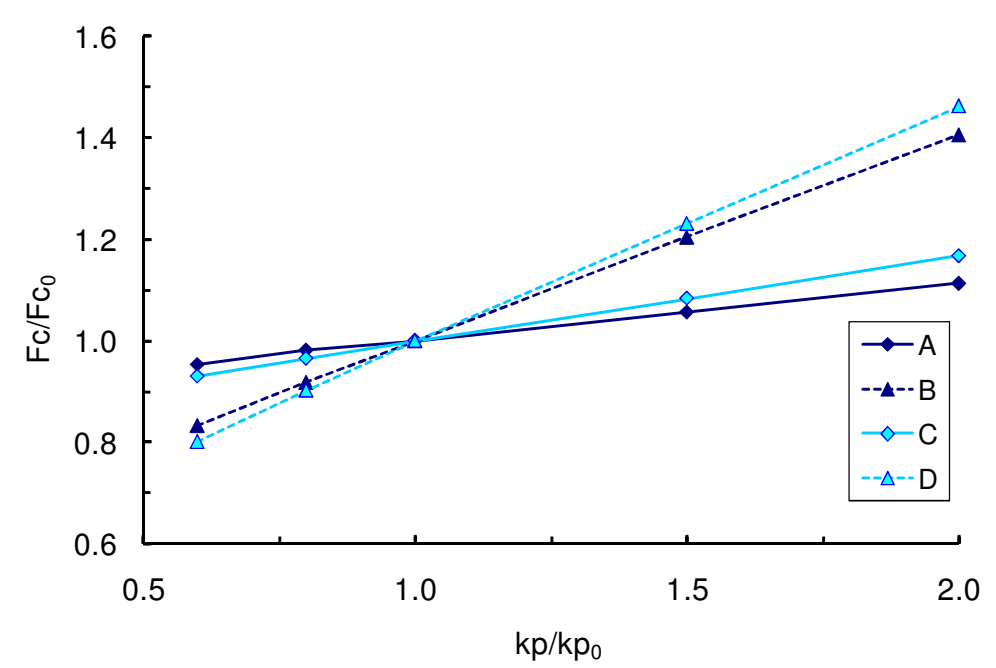

(d) 


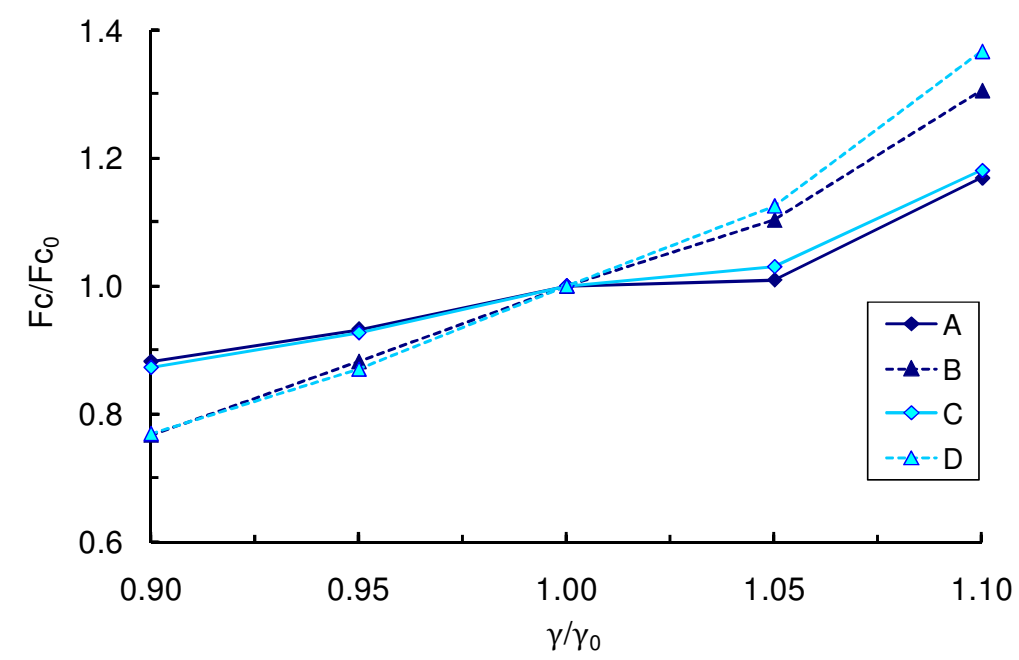

(e)

Fig. 12. Non-dimensional relationship between load factor and: (a) arch thickness; (b) compressive strength; (c) fill depth; (d) mobilized earth pressure coefficient;

(e) physical properties of the fill. A-D indicate the reference bridge being considered. 


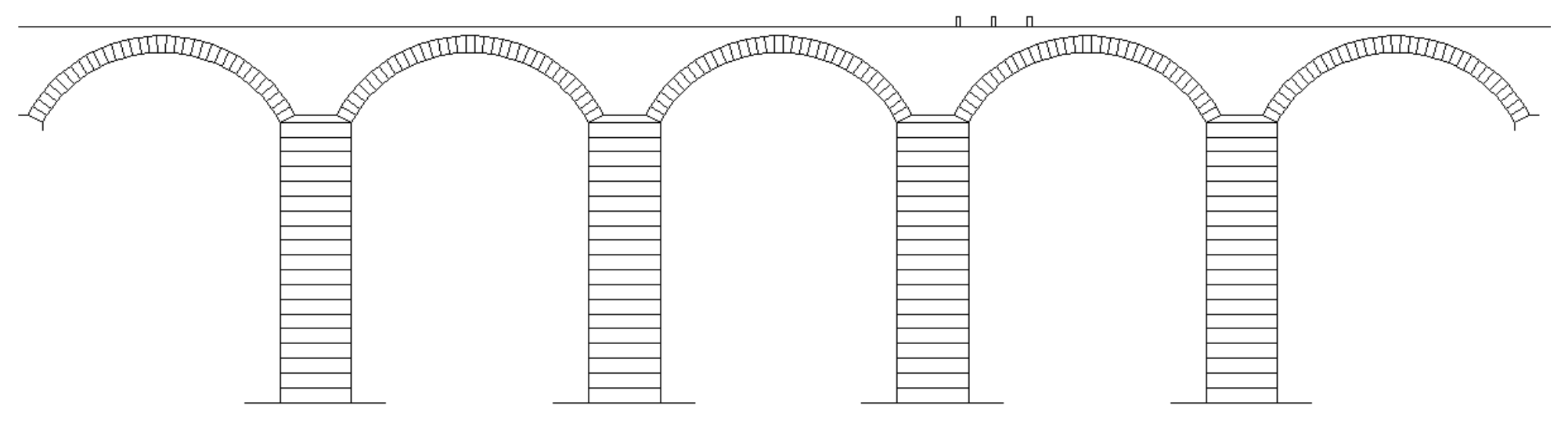

Fig. 13. Elevation view of the multi-span reference bridge C. 


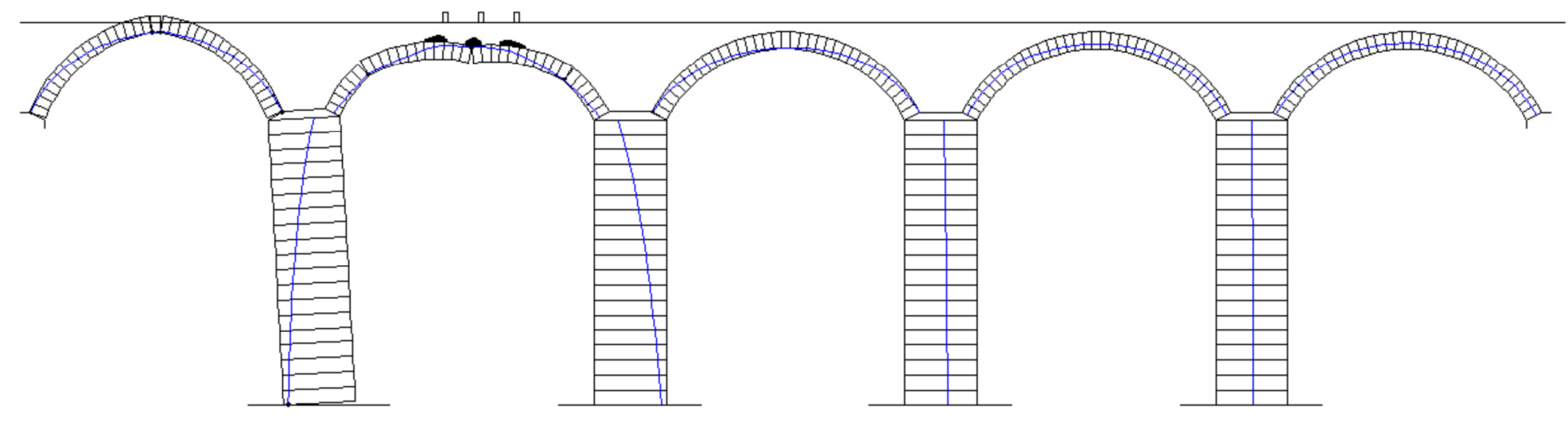

Fig. 14. Collapse mechanism of the multi-span reference bridge C. 


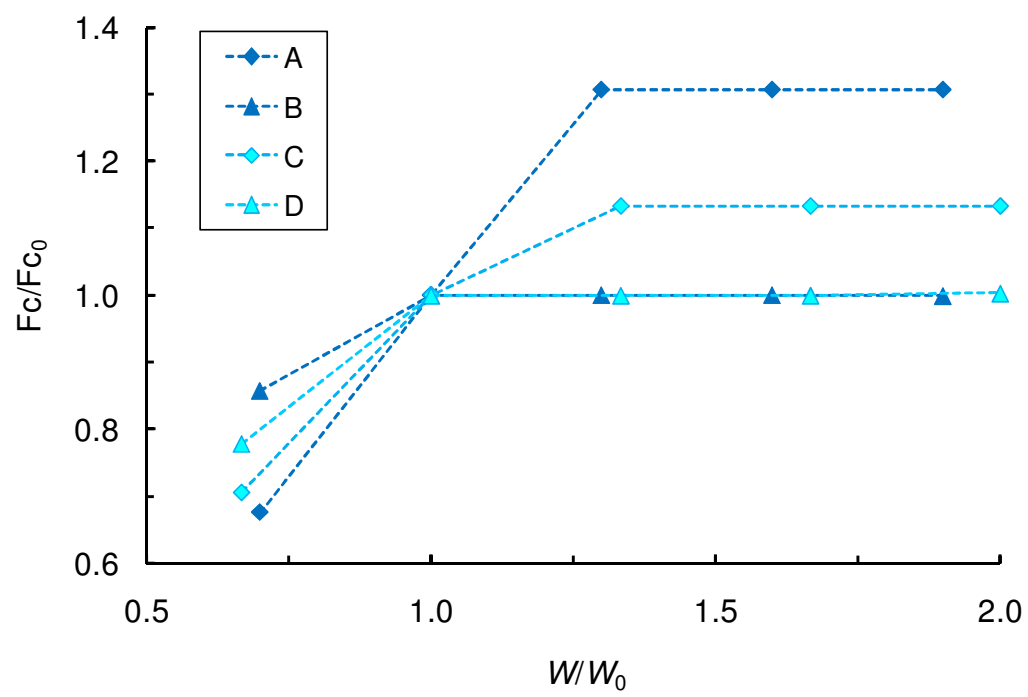

(a)

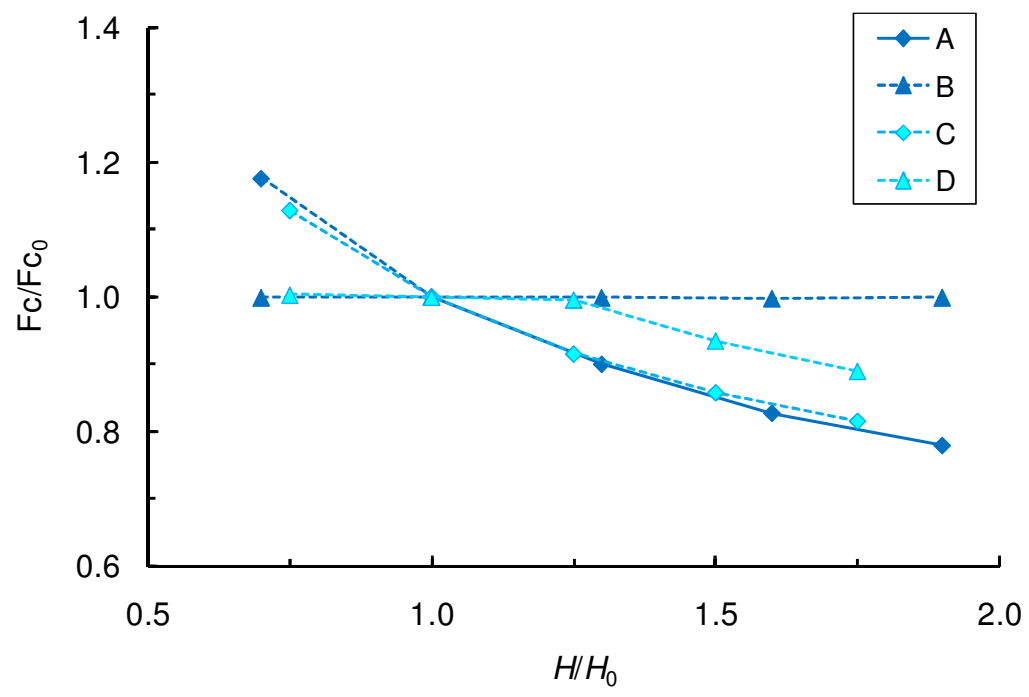

(b)

Fig. 15. Non-dimensional relationship between load factor and: (a) width of piers $(W)$; (b) height of piers $(H)$. A-D indicate the reference bridge being considered. 